\title{
A New Energy Management Technique for PV/Wind/Grid Renewable Energy System
}

\author{
Onur Ozdal Mengi ${ }^{1}$ and Ismail Hakki Altas ${ }^{2}$ \\ ${ }^{1}$ Department of Energy Systems Engineering, Engineering Faculty, Giresun University, 28100 Giresun, Turkey \\ ${ }^{2}$ Department of Electrical and Electronics Engineering, Engineering Faculty, Karadeniz Technical University, 61080 Trabzon, Turkey \\ Correspondence should be addressed to Onur Ozdal Mengi; onurmengi@yahoo.com
}

Received 26 December 2014; Revised 5 February 2015; Accepted 9 February 2015

Academic Editor: Elias Stathatos

Copyright (c) 2015 O. O. Mengi and I. H. Altas. This is an open access article distributed under the Creative Commons Attribution License, which permits unrestricted use, distribution, and reproduction in any medium, provided the original work is properly cited.

\begin{abstract}
An intelligent energy management system (IEMS) for maintaining the energy sustainability in renewable energy systems (RES) is introduced here. It consists of wind and photovoltaic (PV) solar panels are established and used to test the proposed IEMS. Since the wind and solar sources are not reliable in terms of sustainability and power quality, a management system is required for supplying the load power demand. The power generated by RES is collected on a common DC bus as a renewable green power pool to be used for supplying power to loads. The renewable DC power bus is operated in a way that there is always a base power available for permanent loads. Then the additional power requirement is supplied from either wind or PV or both depending upon the availability of these power sources. The decision about operating these systems is given by an IEMS with fuzzy logic decision maker proposed in this study. Using the generated and required power information from the wind/PV and load sides, the fuzzy reasoning based IEMS determines the amount of power to be supplied from each or both sources. Besides, the IEMS tracks the maximum power operating point of the wind energy system.
\end{abstract}

\section{Introduction}

In today's world, the increasing need for energy and the factors, such as increasing energy costs, limited reserves, and environmental pollution, leads the renewable energy to be the most attractive energy source. Since these sources have unlimited supply and they do not cause environmental pollution, they are studied extensively lately and utilized more and more every day. Governments put in new legislations and feed-in-tariffs to encourage the investors to install new renewable energy utilization sites [1-3] and studies on this topic are supported by many foundations.

Renewable energy sources consist of solar energy, wind energy, geothermal energy, and wave energy which are considered to be endless since they exist naturally and they always renew themselves [4]. It is one of the important topics that researchers and scientist work on to obtain energy from these sources and use this energy by transforming it into the form of electrical energy.
Solar and wind energies have a distinguished place among these energy types. There are wind and sun everywhere on earth; therefore, there is more intense study on these sources. The aim is not only to obtain the energy but also to turn the energy to proper values, manage the existent energy, and terminate the harmonics. While managing all these, lowering the cost of the system in every step is taken into consideration. Today, producing electrical energy from these renewable sources appears to be the main objective [5-7].

The combined operation of these systems is far more complex than operating them separately. In a system with only solar or wind energy, just one element is controlled. In a hybrid scheme, both sources are controlled individually and simultaneously depending upon the operating conditions and energy demand. During low sunlight conditions, photovoltaic (PV) solar panel cannot supply consistent power. Similarly, wind turbine will not work in conditions without wind. In this case, the required energy must have the structure to make up the lack of energy in conditions when this system 
does not work regularly or the composition produces less energy than the requirement. Power management assures that the system works efficiently while preventing the lack of energy in loads. Here it is aimed at obtaining clean and sustainable energy in stable frequency and definite voltage. While or after obtaining the energy, harmonics must be definitely controlled.

Power management is important to assure both economical and efficient work of the system in combined usage of renewable energy sources. Variable weather conditions, day-night conditions, and rapid change in voltages make this necessary. Power management can be achieved by using maximum power point tracking (MPPT) [8] devices in order to determine the most efficient operating point of a system in a particular weather condition and by switching the systems so that they become active to support each other dynamically. It is important to keep the backup batteries full in times when there is neither sun nor wind. Without backup batteries there will be no energy in the system. In this case, for instance, it is computerized control mechanism's duty to link the system to the grid, connect the generator or determine, and manage the related situations.

Nowadays renewable energy sources are structured in two ways as grid connected and standalone. Renewable energy sources as solar energy and wind energy can be used to feed loads far from the grid especially the home type ones. However, there are problems in these types of systems when there is no sun or wind. Users become fully powerless after the batteries are flat which are used as backup systems. An alternative situation to this is to connect the loads to the grid if they are close to it, in conditions that there is no sun or wind and the batteries are empty [9].

In literature review, it can be seen that there are many researches which include wind turbine and PV solar panels used together $[10,11]$ and the loads are fed with the energy obtained and power management conducted [12-14]. The main aim here is to gain maximum power according to environmental conditions and whether the obtained energy is to be fed by wind energy system (WES) or by PV solar panels systems according to changing load conditions. Similar to wind turbines and PV solar panels, there are several studies related to energy management and power flow in electrical power systems and other energy generation units [15-17].

Energy sources such as PV solar panels, wind turbines, fuel cell, and diesel generator can be used both as standalone or hybrid. There are many studies and utilizations such as wind/PV [10, 11], wind/fuel cell [18], PV/battery [19], wind/battery [20], PV/wind/fuel cell [21], PV/fuel cell [22], $\mathrm{PV} /$ wind/battery [23], and PV/grid [24]. The studies aim to increase power quality, ensure energy sustainability, and stabilize the amplitude and frequency of the voltage on the load side on a definite value. Besides, the energy management occupies an important part of the studies related to renewable energy utilization schemes [13]. Energy management in renewable energy systems deals with both source and user side control issues to keep the overall system running smoothly $[25,26]$.

In addition to this, MPPT is one of the important parts of the work, because IEMS calculates maximum power in WEC system. There are various methods which produce MPPT to obtain maximum power from RES. It is tried to run the system continuously at this point by defining the maximum power point with more efficient controls of power electronics converters. While there are studies for calculation of instantaneous generated power decided according to measurements of the environmental conditions, studies which focus on the efficient controls are conducted for similarly used engines to produce maximum power production. It is aimed that the wind turbines work with maximum efficiency [27-33]. In this study, there is an MPPT designed in a different way from these methods. Here, smart control software continuously and accurately calculates the maximum power that can be obtained from the wind turbine. MPPT is an important part of IEMS. Moreover, it is different than the other methods which include expensive control and measurement methods in that it is much cheaper and simpler.

In this study, a power management system will feed the loads from a hybrid power generation system consisting of PV solar panels, WES and grid. WES consists of a different and new MPPT method. The hybrid system is connected to a common DC bus, which is used as a power pool for sustainability. PV system is also connected to a backup battery unit to be charged for emergency usage when additional power is needed. In addition to the source side, the load side management is also very important for the renewable energy systems and also considered in this study.

Besides, energy management software can rapidly and continuously respond without being bounded to environmental conditions, which keep continuously some amount of power in reserve and during instantaneous load changes control the system efficiently. This study is different from the others in its being efficient management approach and having different, cheaper, and simpler peak power point tracking.

\section{System Description and Methodology}

The overall scheme of the proposed hybrid renewable power management system is given in Figure 1. The system consists of PV and wind power generating units and a utility grid as hybrid electrical sources. These three generating units are connected to a DC power pool over the required converters. A backup battery group is also connected to PV system in order to store the extra generated solar power when all generated power from the PV is not delivered to the load. AC load types are considered in the system and they are connected to AC power bus, which is fed from the common DC power pool. Data collected from source side and load side is transferred to a computer to be evaluated for decision making process of the power management system.

The power management algorithm (PMA) is developed to operate both photovoltaic energy system (PVES) and wind energy system (WES) at the maximum power they can generate under various environmental conditions while maintaining power supply demand of the load side at required amount. Therefore the power management includes maximum power point tracing of PVES and WES, energy storage, utility connection, and load switching. Besides, the power 


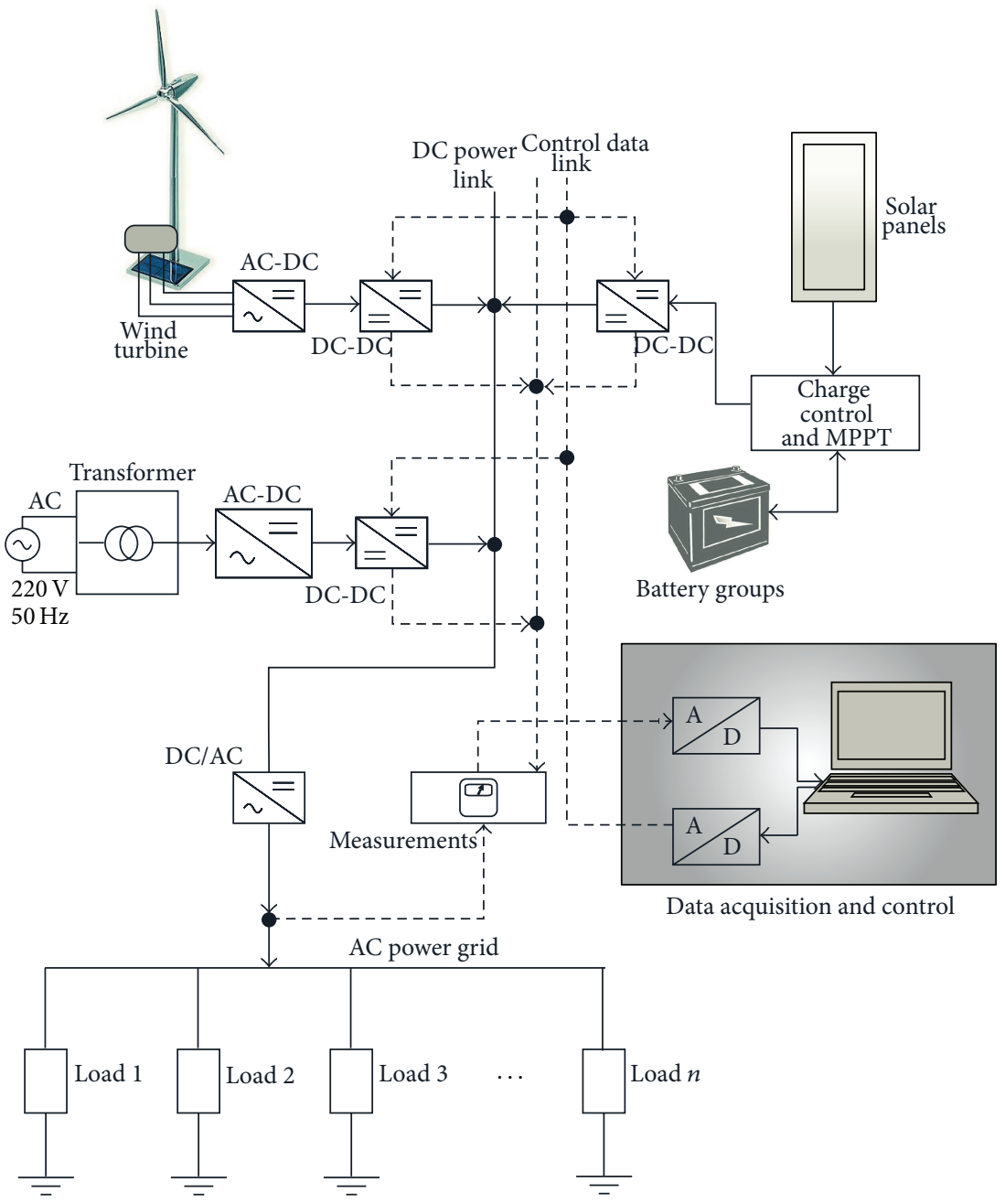

FIGURE 1: Renewable power generation system and energy management.

quality issues such as harmonic elimination, voltage sags, voltage increments, frequency deviations, and voltage magnitude are included in the management system. It is obvious that there are too many inputs and parameters into the management decision algorithms. A fuzzy logic based decision making algorithm is developed and used for this multi-input, multiobjective system.

2.1. PV System. PVES is modeled using the well-known characteristic equation of PV cell. The voltage-current equation of a PV cell is based on photocurrent of a P-N junction semiconductor. The photocurrent is a function of solar irradiation and changes with the sunlight. The voltage across the connection terminal of the $\mathrm{P}-\mathrm{N}$ device varies as a function of the photocurrent. When there is a path across the terminals of the P-N device, which is the photovoltaic cell, external current flows through this path, if there is a load on the path then through the load. The maximum value of this external current, or, in other words, load current, is the short circuit current and assumed to be equal to the generated photocurrent. It is observed that as the cell current increased, the cell gets heated resulting in a decreased terminal voltage. Therefore, considering this voltage decrement and reverse saturation current of the $\mathrm{P}-\mathrm{N}$ diode, the terminal voltage of a single $\mathrm{PV}$ cell is written as in

$$
V_{C}=\frac{A \times k \times T_{a}}{e} \ln \left(\frac{I_{\mathrm{PH}}+I_{S}-I_{C}}{I_{S}}\right)-R_{S} \times I_{C}
$$

$I_{C}$ : cell output current $(\mathrm{A}), I_{\mathrm{PH}}$ : photocurrent, function of irradiation level and junction of temperature $(\mathrm{A}), I_{S}$ reverse saturation of current of diode $(\mathrm{A}), V_{C}$ : cell output voltage $(\mathrm{V})$, $R_{S}$ : series resistance of cell, $e$ : electron charge $(1.6021917 \times$ $\left.10^{-19} \mathrm{C}\right), k$ : Boltzmann constant $\left(1.380622 \times 10^{-23} \mathrm{~J} /{ }^{\circ} \mathrm{K}\right), T_{a}$ : reference cell ambient temperature $\left({ }^{\circ} \mathrm{K}\right)$, and $A$ : curve fitting factor (100).

PV solar cells are connected in series and parallel combinations and manufactured as PV modules to be used more effectively in commercial applications. The voltage of a PV module is determined by the PV cells connected in series and the current of a PV module is determined by the number of parallel connected series branches. The required load power 


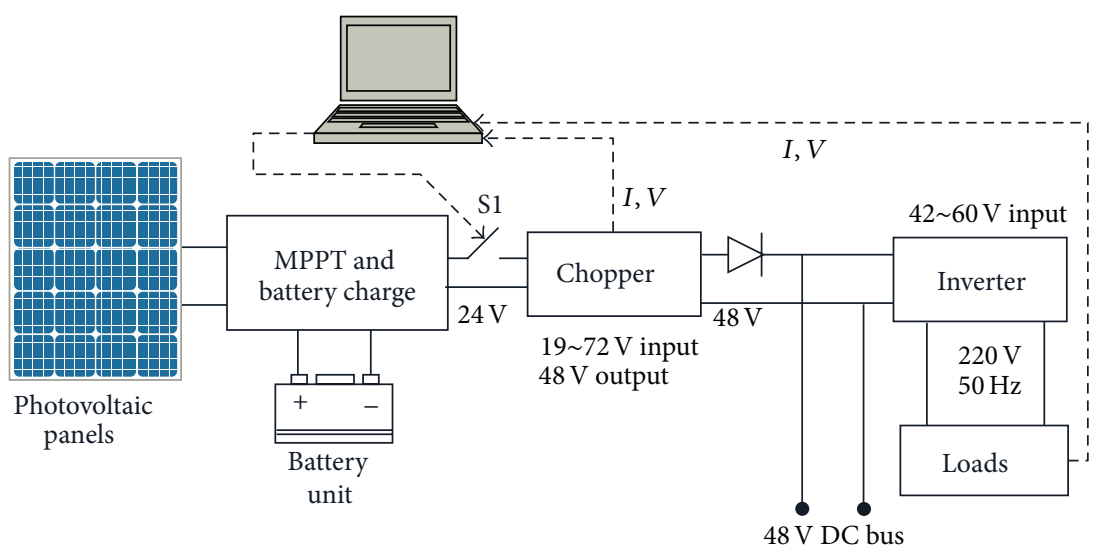

FIgURE 2: The PV power generation part of the system.

is then obtained by connecting the PV modules in series and in parallel yielding the PV arrays [24].

The power flow path from PV power generation unit to the load is shown in Figure 2. Four PV modules connected 2 in series and 2 series branches in parallel are used here to get an array with 42 volts and 5 amperes maximum under good weather conditions.

PV array and battery groups are connected to each other with a device including a battery charging regulator and maximum power point tracker. When the sunlight is not sufficient, the batteries step in and supply the necessary power to the loads. The MPPT is used to transfer the maximum generated power from the PV array and charge the batteries if any power is left after feeding the load. This unit is MOTECH PV4830 MPPT charge controller. The batteries are also charged from the DC power bus when the sunlight is insufficient. A battery charge regulator with $12 / 24 / 36 / 48 \mathrm{~V}$ and $30 \mathrm{~A}$ is used as a charging interface device. Total peak power generated by the PV array under good weather conditions is about $320 \mathrm{Wp}$. Since the value of the generated voltage from the $\mathrm{PV}$ array changes depending upon sunlight, a DC chopper (19 72 V DC input voltage) is used to keep the DC voltage from the PV panels at $48 \mathrm{~V}$. This chopper is boost converter. The diode that is used after the chopper is located in order to protect the chopper. It is a kind of electronic fuse. It is a diode that prevents reverse current flow with a high current. This is the magnitude of the DC bus voltage, which is inverted to $220 \mathrm{~V}, 50 \mathrm{~Hz}$ AC voltage by a boost-up inverter. In this scheme, the current and voltage data from the loads are measured and transferred to the computer, besides the input voltage and output current of the chopper to be used in decision making process.

2.2. Wind Turbine Emulator and WES. The wind turbines convert the mechanical energy that is produced by the wind to electrical energy. To use this electrical energy a voltage and a frequency regulation has been needed. The model of the wind turbine is developed by the basis of the steady state power characteristics of the turbine.

Calculations of induction machines are completed in $d-q$ axis frame. Figure 3 shows the depictions of axis frames.

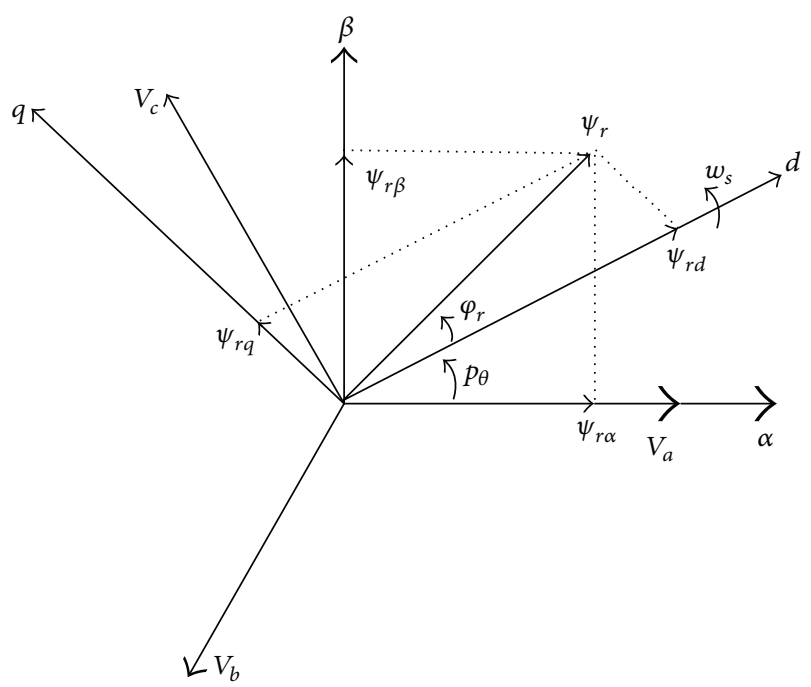

Figure 3: Phase depiction of components of $d-q$ axis frame in rotor flux vector.

Here we can obtain

$$
\left[\begin{array}{c}
V_{s d} \\
V_{s q}
\end{array}\right]=\left[\begin{array}{cc}
\operatorname{Cos} \theta_{s} & -\operatorname{Sin} \theta_{s} \\
\operatorname{Sin} \theta_{s} & \operatorname{Cos} \theta_{s}
\end{array}\right]\left[\begin{array}{c}
V_{s \alpha} \\
V_{s \beta}
\end{array}\right]
$$

After the necessary conversions are completed, $d-q$ axis frame equivalent of the machine is obtained as shown in

$$
\begin{aligned}
{\left[\begin{array}{c}
V_{s d} \\
V_{s q} \\
0 \\
0
\end{array}\right]=} & {\left[\begin{array}{cccc}
R_{s} & 0 & 0 & 0 \\
0 & R_{s} & 0 & 0 \\
0 & 0 & R_{r}^{\prime} & 0 \\
0 & 0 & 0 & R_{r}^{\prime}
\end{array}\right]\left[\begin{array}{c}
i_{s d} \\
i_{s q} \\
i_{r d} \\
i_{r q}
\end{array}\right] } \\
& +\left[\begin{array}{cccc}
L_{s} & 0 & L_{m} & 0 \\
0 & L_{s} & 0 & L_{m} \\
L_{m} & 0 & L_{r}^{\prime} & 0 \\
0 & L_{m} & 0 & L_{r}^{\prime}
\end{array}\right] \frac{d}{d t}\left[\begin{array}{c}
i_{s d} \\
i_{s q} \\
i_{r d} \\
i_{r q}
\end{array}\right]
\end{aligned}
$$




$$
\begin{gathered}
+\left[\begin{array}{cccc}
0 & -\omega_{s} L_{s} & \omega_{s} L_{m} & 0 \\
\omega_{s} L_{s} & 0 & 0 & \omega_{s} L_{m} \\
\omega_{r} L_{m} & 0 & 0 & -\omega_{r} L_{r} \\
0 & \omega_{r} L_{m} & \omega_{r} L_{r} & 0
\end{array}\right]\left[\begin{array}{c}
i_{s d} \\
i_{s q} \\
i_{r d} \\
i_{r q}
\end{array}\right] \\
M_{e}=p L_{m}\left(i_{s q} i_{r d}-i_{s d} i_{r q}\right)=J \frac{d^{2} \theta}{d t^{2}}+B \frac{d \theta}{d t} .
\end{gathered}
$$

Angular frequency $\omega_{s}$ is as shown below:

$$
\omega_{s}=\omega_{r}+p \omega .
$$

Here $\omega_{s}$ represents the angular frequency of stator fluxes and $\omega_{r}$ represents rotor fluxes angular frequency and $\omega$ angular speed of machine shaft, also represented by

$$
\omega_{s}=\frac{d \theta}{d t}=2 \pi \frac{n_{s}}{60}
$$

and $n_{s}$ is synchrony speed. $\omega$ is shown in

$$
\omega=\frac{d \theta}{d t}
$$

And $n_{s}$ is as in

$$
n_{s}=60 \frac{f_{s}}{p} \text {. }
$$

Here $f_{s}$ represents the stator flux value.

The relation between flux and current in $d-q$ axis frame is as in (9) and (12):

$$
\begin{aligned}
& \psi_{s d}=L_{s} i_{s d}+L_{m} i_{r d} \\
& \psi_{s q}=L_{s} i_{s q}+L_{m} i_{r q} \\
& \psi_{r d}=L_{r}^{\prime} i_{r d}+L_{m} i_{s d} \\
& \psi_{r q}=L_{r}^{\prime} i_{r q}+L_{m} i_{s q} .
\end{aligned}
$$

The state-space model according to $(0, d, q)$ stator and rotor axis frames of the system can be seen in (13) and (17) [34]:

$$
\begin{aligned}
\frac{d i_{s d}}{d t}=\frac{1}{\sigma L_{s}}[ & -R_{E} i_{s d}+\sigma L_{s} \omega_{s} i_{s q} \\
& \left.+\frac{L_{m} R_{r}^{\prime}}{L_{r}^{\prime 2}} \psi_{r d}+p \omega \frac{L_{m}}{L_{r}^{\prime}} \psi_{r q}+V_{s d}\right]
\end{aligned}
$$

$$
\begin{gathered}
\frac{d i_{s q}}{d t}=\frac{1}{\sigma L_{s}}\left[-R_{E} i_{s q}+\sigma L_{s} \omega_{s} i_{s d}\right. \\
\left.-p \omega \frac{L_{m}}{L_{r}^{\prime}} \psi_{r d}+\frac{L_{m} R_{r}^{\prime}}{L_{r}^{\prime 2}} \psi_{r q}+V_{s q}\right] \\
\frac{d \psi_{r d}}{d t}=\frac{R_{r}^{\prime} L_{m}}{L_{r}^{\prime}} i_{s d}-\frac{R_{r}^{\prime}}{L_{r}^{\prime}} \psi_{r d}+\omega_{r} \psi_{r q} \\
\frac{d \psi_{r q}}{d t}=\frac{R_{r}^{\prime} L_{m}}{L_{r}^{\prime}} i_{s q}-\omega_{r} \psi_{r d}-\frac{R_{r}^{\prime}}{L_{r}^{\prime}} \psi_{r q} \\
M_{e}=p \frac{L_{m}}{L_{r}^{\prime}}\left(i_{s q} \psi_{r d}-i_{s q} \psi_{r q}\right)=J \frac{d \omega}{d t}+B \omega .
\end{gathered}
$$

Consider the following symbols:

$L_{s}$ : stator winding inductance $(\mathrm{H})$,

$L_{r}$ : rotor winding inductance $(\mathrm{H})$,

$M_{m}$ : maximum mutual inductance between rotor and stator $(\mathrm{H})$,

$R_{s}$ : stator phase resistance $(\Omega)$,

$R_{h}$ : circle peace resistance between two strips $(\Omega)$,

$R_{C}:$ strip resistance $(\Omega)$,

$M_{s s}$ : converse inductance between stator phase windings $(\mathrm{H})$,

$M_{r r}$ : mutual inductance between rotor strips $(\mathrm{H})$,

$\mu_{0}: 4 \pi 10^{-7}$,

$g:$ air gap $(\mathrm{m})$,

A: air gap segment $\left(\mathrm{m}^{2}\right)$,

$p$ : number of pole pairs,

$w_{s}$ : stator angular frequency,

$w_{r}$ : rotor angular frequency,

$w$ : synchronous speed,

$f_{s}$ : stator frequency,

$\psi_{s}:$ stator flux vector,

$\psi_{r}$ : rotor flux vector,

$\theta$ : machine axis rotation angle,

$J$ : viscosity moment,

$B$ : viscosity friction coefficient.

The WES emulator is established by coupling two squirrel cage asynchronous machines together as seen in Figure 4. The power of the machine to be used as the prime mover for representing the wind turbine is selected as $5 \mathrm{~kW}$ and the power of the other machine used as the generator is selected as $3 \mathrm{~kW}$ so that the generator can also be operated at overpower conditions to expand the analysis of the operating cases.

The machine on the left is a prime mover representing the wind turbine and is controlled with a $V / f$ speed controller. Depending on the wind speed, the output voltage of the generator, the second machine from the left, changes between 


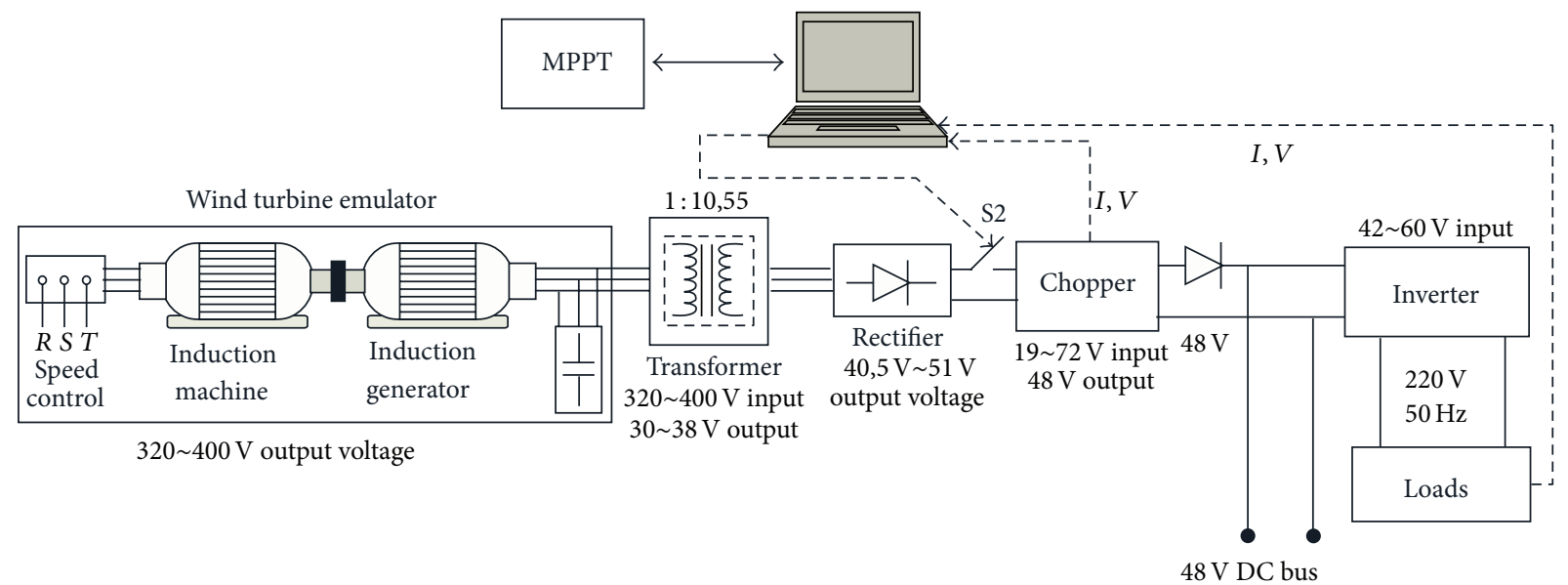

FIGURE 4: Feeding the loads with power generated from WES model.

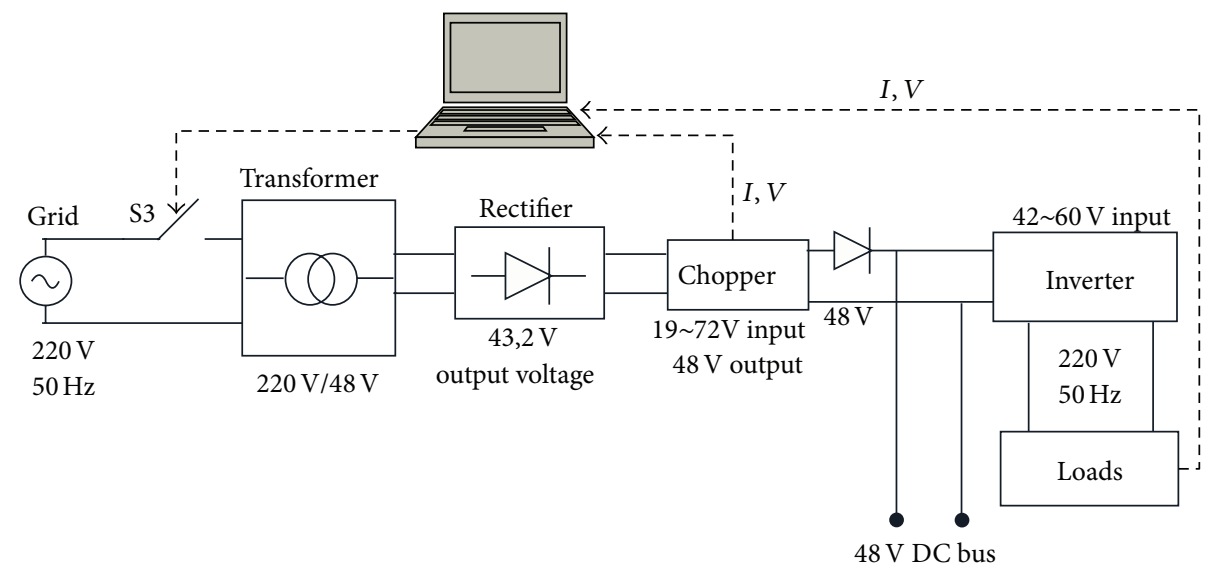

FIGURE 5: Grid connection structure in the system.

$320 \mathrm{~V}$ and $400 \mathrm{~V}$. Three phase voltage magnitudes obtained from the generator are reduced to a lower level using a step down transformer with a ratio of $380 \mathrm{~V} / 36 \mathrm{~V}$. Therefore, transformer output voltages change between $30 \mathrm{~V}$ and $38 \mathrm{~V}$. The output voltage magnitude of 3-phase full bridge diode rectifier is calculated as in

$$
U_{o}=1,654 \cdot U_{R_{\mathrm{MAX}}},
$$

where $U_{o}$ is rectifier output voltage $(\mathrm{V})$ and $U_{R_{\mathrm{MAX}}}$ is the maximum value of single phase voltage $(\mathrm{V})$. Full bridge rectifier output voltage changes from $40,5 \mathrm{~V}$ to $51 \mathrm{~V}$. A DC chopper is used to convert this variable voltage to a $48 \mathrm{~V}$ constant DC to be connected to common DC bus, which has a $48 \mathrm{~V}$ constant DC voltage.

The reactive power to generate energy at this point is supplied with a condenser group. Later on, this three-phase voltage which is rectified is sent through a chopper and it is brought to $48 \mathrm{~V}$ value and connected to common DC bus. Then an inverter is used to convert this $48 \mathrm{~V}$ voltage to $230 \mathrm{~V} / 50 \mathrm{~Hz}$ alternating voltage and the loads are fed. Here the current and voltage information on the loads and copper input voltage and output current is measured and these values are transferred to the computer.
2.3. Grid Connection. The proposed renewable energy scheme consists of two-type operating conditions. The first case described in previous sections is the one supplying power to individual loads where the utility grid is not available or not connected. The second case deals with utility connected renewable energy scheme as shown in Figure 5. Hence power generated from each power generation system is collected in $48 \mathrm{~V}$ direct current bus.

As shown in Figure 4, the utility voltage is converted to $48 \mathrm{~V}$ DC constant value to be connected to $48 \mathrm{~V}$ common DC bus as it is done for wind and PV systems.

Data collected from various parts of the system is transferred to the computer and used for control and decision making processes. The interfacing between the real system and the computer is established by NI USB 6259 data acquisition card.

2.4. Power Management and Sustainability. The electrical power generated by renewable sources such as wind and solar power is affected by environmental conditions resulting in problems in load part. When there is no sun or the weather is cloudy, the power amount to be generated by solar energy 


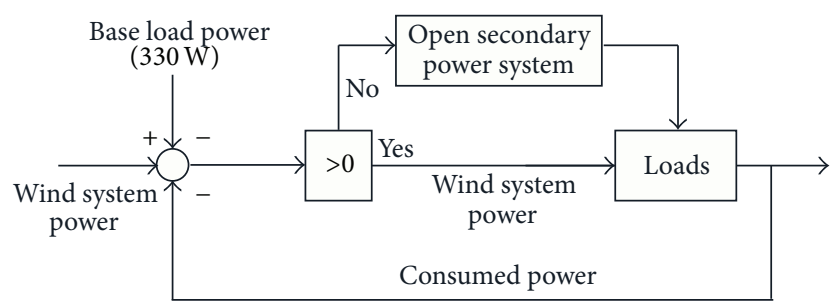

FIGURE 6: Basic block diagram of power management system.

changes. Accordingly, wind does not blow at the same speed all the time; it is discontinuous. Henceforth, energy amount to be generated from these sources are variable.

In particular in low powered applications, for instance, while supplying energy to a house from these sources, it is a problematic situation to have a power cutoff while watching a TV. Power sources must be efficiently operated in order to avoid such situations.

Proposed PMA and decision making process are developed to prevent problems like voltage sags and discontinuities that occur due to either weather changes or sudden load changes. The intelligent decision making algorithm manages the energy storage and usage switching patterns so that energy sustainability is guaranteed.

General block diagram of the power management scheme is given in Figure 6 . The total generated power from the wind is used as the primary supply power, which is used to supply base load power. As long as the wind power is sufficient, the secondary power system is kept off and additional generated power is stored. When the wind power is less than the required load power then the secondary power system, which is solar and/or utility grid, is activated. The service order of the secondary power system goes as solar PV, storage, and utility grid. Since the utility grid requires additional payment, it is put at the end of the list and the priority is given to the wind and PV arrays [35]. The load power is calculated as in

$$
P_{\text {Load }}=P_{\text {WindSystem }}+300 \mathrm{~W} \text {. }
$$

2.5. Power Management System Design. In order to solve sustainability and power quality problems, the power transfer from the renewable sources to load must be managed in a proper way. Therefore a PMA system has been designed to prevent power discontinuity and overvoltage and undervoltage operations so that the loads operate properly. The power management system is automated in an efficient way by switching on or off the sources and backup units. For example, if the wind power is sufficient enough to feed the load, then there is no need for the auxiliary sources of PV, backup batteries, and the utility. If the wind power decreases, the gap is filled by PV first, then batteries, and then the utility. The overgenerated power is stored and used only when needed.

The overall energy generation system established experimentally can be seen in Figure 7. In this system, the electrical power is generated by wind generator and PV solar panels. The utility is reserved as an auxiliary source to be used when needed. The power from the PV system is used to supply power to the load when the wind power is not sufficient and to charge the batteries when there is sufficient wind and sun power. Data collected from various parts of the overall system is transferred to the computer to be analyzed.

The main objective of employing a power management algorithm in power systems where the renewable energy is the priority supply is to have the power ready to be used and feed the load continuously. For this reason, the peak power value from both WES and PV solar panels must be calculated. MPPT device used for PV solar panels handles this duty on its own. Therefore, there is no need to calculate the peak power calculation in PV solar panels. MOTECH PV4830 MPPT charge controller calculates MPP by itself. However, the peak power value to be obtained from WES must be defined. The priority supply is WES in this system. At the same time, since the changing environmental conditions affect the amount of energy to be produced, power management is planned to avoid this effect by leaving a base power in the system. The base power is the power that must be supplied all the time for the loads with nonstop operating behaviors. The base power in the proposed system is defined as $300 \mathrm{~W}$, which can be easily changed inside the software if desired. The system is designed to feed maximum $1 \mathrm{~kW}$, which is more than three times the base power. If the environmental conditions are sufficient, which means there is enough sun and wind, wind energy generation system and PV solar panels generation system produce the maximum power they can, and the installed power can rise over $2 \mathrm{~kW}$ value. The main operational principle of the system is summarized as follows.

(1) Initially the system is started with both solar and wind energy in service.

(2) After the transients are over and measurements are done, WES or PV solar panels system will be kept working according to load condition. If the environmental conditions are not suitable for PV solar panels or WES to operate individually, both will operate. When the present condition does not meet the energy requirements of the load, grid will.

(3) If WES can handle the load power requirement alone, it will operate. PV solar panels will be used to charge the batteries only.

(4) If WES does not generate sufficient power, PV solar panels will engage and both will operate together. If both are insufficient, then the grid will engage.

(5) If there is no wind, PV solar panels will feed the loads.

(6) When there is no sun and the batteries are empty or the battery cannot feed the loads with its actual power amount, the grid will begin to operate. These steps bring up the importance of the following:

(1) the operating time of each unit,

(2) turnoff time of each unit,

(3) the amount of load at present conditions.

Since only the wind energy will operate constantly, these lists of rules are processed by taking the measurements from wind energy system into consideration.

(1) $300 \mathrm{~W}$ power will be supplied as the permanent power in the system. The wind turbine emulator is operated at various speeds in order to represent the generated wind 


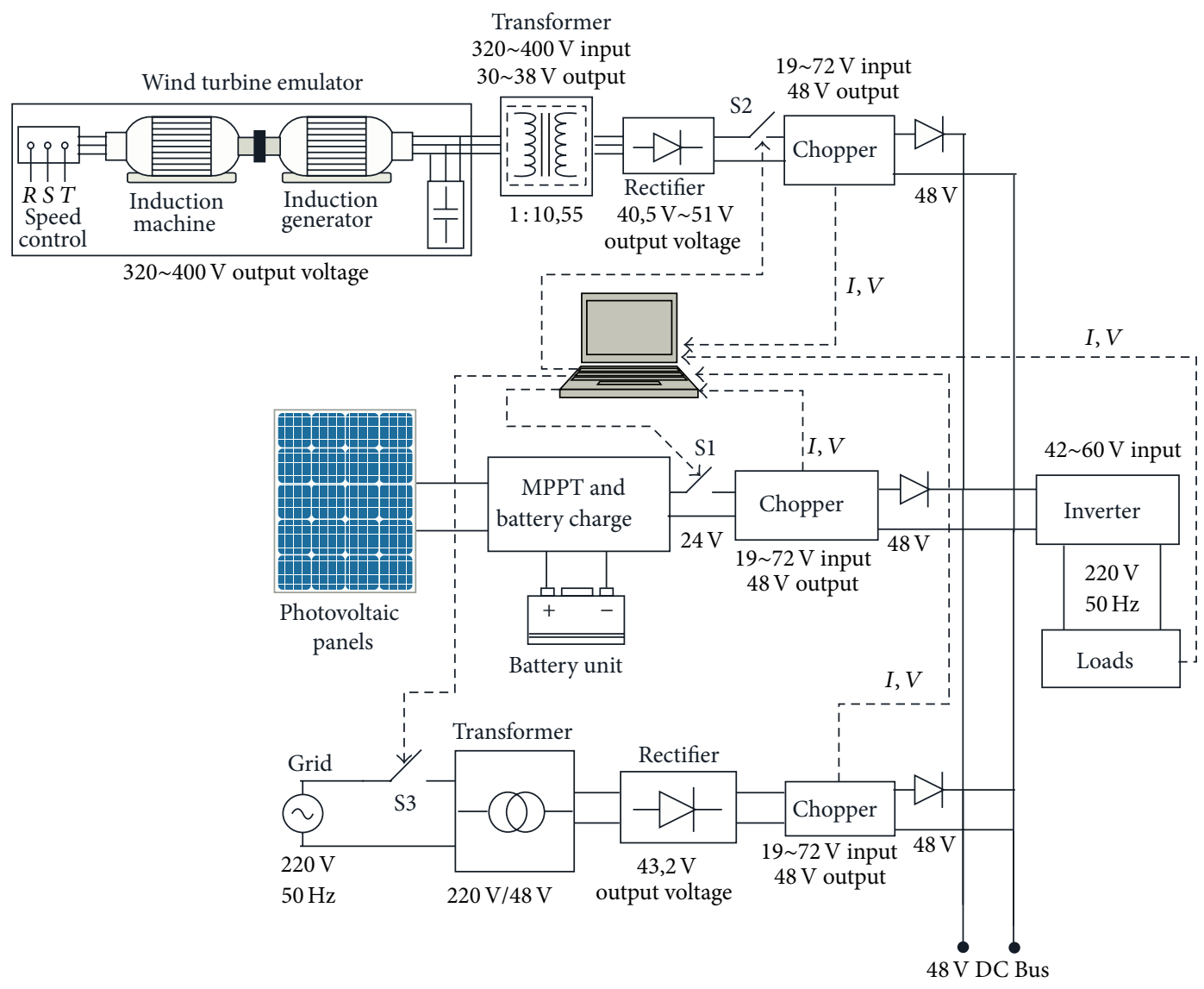

FIGURE 7: PV solar panels-WES-grid system.

power properly. The emulator has been set up so that the generated power will not be sufficient with the base power under a speed of $35 \mathrm{~Hz}$. During this condition, solar energy will automatically begin to operate.

(2) $V_{\mathrm{DC} / \mathrm{DC}_{G}}$ chopper input voltage value is different in asynchronous motor driver frequencies. For instance, when the load power is $500 \mathrm{~W}$, the generated voltage becomes $47.3 \mathrm{~V}$ at $44 \mathrm{~Hz}$ and $45.4 \mathrm{~V}$ at $43 \mathrm{~Hz}$. It will decrease other value down to $31.5 \mathrm{~V}$ at $37 \mathrm{~Hz}$. The relationship between voltage and frequency is used to estimate the operating frequency.

(3) Considering both $I_{\mathrm{DC} / \mathrm{DC}_{O}}$ and $V_{\mathrm{DC} / \mathrm{DC}_{G}}$ values, asynchronous motor driver frequency, power dissipated at that moment, and maximum load values at that driver frequency can be detected. This case is also used to determine switch on or switch off times of PV solar panels. It should not be forgotten that $300 \mathrm{~W}$ power will always be in the system as the base power to be supplied.

(4) Similarly when the PV solar panels are on, the generated voltage from the PV panels to the chopper decreases as load power increases. Using the measured values from this operating case, it is possible to find out how much power should be generated by the panels to feed the load. Chopper input voltage value will decrease as the batteries discharge. The batteries are assumed to be insufficient to feed the load when their voltage drops down below $21 \mathrm{~V}$. If the sunlight is not enough to generate the required power to the load, the batteries also will not be usable with an output voltage less than $21 \mathrm{~V}$.

(5) While PV solar panels are feeding the loads, after the WES begins to operate, some of the required power is supplied from WES. If WES can supply all of the load power, then PV solar panels are switched to charge the batteries.

(6) It is important to get measurements of these operating cases continuously in order to respond immediately in sudden load changes. The base power demand is $300 \mathrm{~W}$. If a sudden load change increases over $300 \mathrm{~W}$, the system is disconnected. For example, when the load power is $500 \mathrm{~W}$ when WES can give maximum $500 \mathrm{~W}$, PV solar panels must operate so that in a $300 \mathrm{~W}$ sudden load increase the loads can be fed without the system failure. This action is taken to prevent system shutdown in power changes resulting from sudden charges according to the environmental conditions at the time.

(7) The grid connection is established when neither the sun nor the wind are sufficient enough to supply $300 \mathrm{~W}$ base power demand.

Flow diagram of power management program is given in Figure 8 .

2.6. Fuzzy Logic Reasoning (FLR) and Calculation of Peak Wind Power. Fuzzy logic has so many applications in industry. Fuzzy logic reasoning (FLR) algorithms are generally 


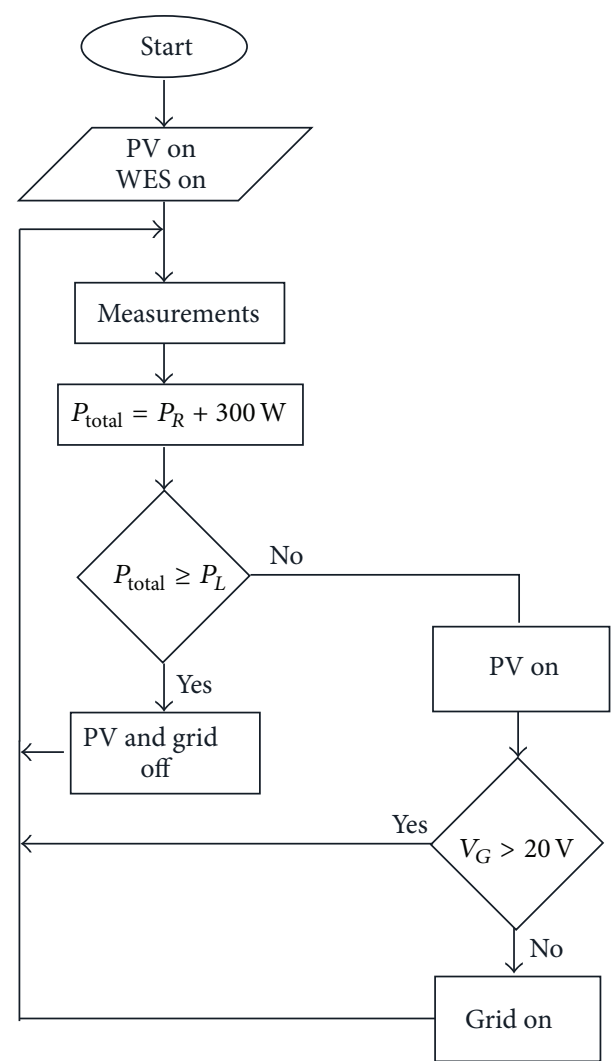

FIGURE 8: Simplified flow diagram of power management program.

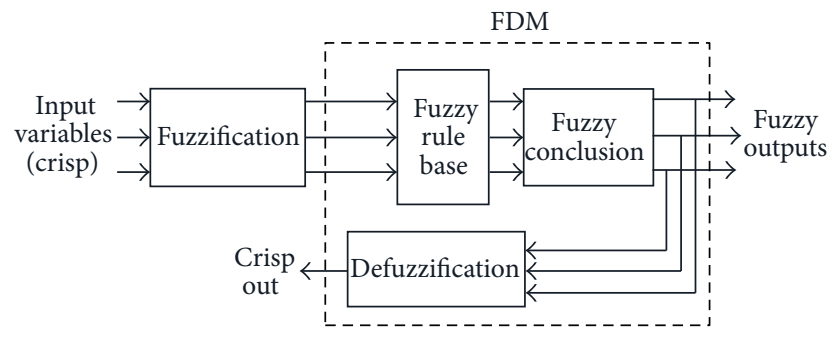

Figure 9: Fuzzy decision maker.

used in fuzzy decision makers (FDM), which find applications in systems that require a conclusion from uncertain input data. Since the wind conditions are not certain and are not easily predictable, the power generated by the wind energy system becomes uncertain including the maximum generated power as well. Therefore a fuzzy reasoning algorithm is developed to determine the maximum power generated by WES. The fuzzy reasoning applied to determine the maximum power of the WES is represented in Figure 9. Fuzzy decision maker's MATLAB/Simulink model is given in Figure 10.

A FDM usually gets fuzzy inputs and evaluates them in the rule base system, which is set up earlier representing the input-output relations of the uncertain system in terms of fuzzy membership functions and fuzzy rules (FR). The FR is the evaluation of the rules to yield fuzzy conclusions from fuzzy inputs-fuzzy rules interactions, if the input variables are crisp. Certain input values are rated here. Thus, these values can be included in a value range that can be used by the controller and then it can be expressed verbally. In addition, it becomes a member of a group that has clear boundaries. Then they are fuzzified to fuzzy values. Similarly if the output is required as crisp value, then the concluded fuzzy outputs are converted to crisp values by the process called defuzzification.

In this study, the input values to the FDM are the current and voltage measured from the WES. The generated rules are used to relate the input voltage and current with the power of the WES depending upon the wind speed conditions. FR algorithm in the FDM is used to obtain maximum power generation from WES for uncertain and unpredictable speed conditions. The designed FR based FDM is modeled in Matlab/Simulink environment as shown in Figure 10. The maximum wind power value is determined by FDM using chopper's input voltage $V_{\mathrm{DC} / \mathrm{DC}_{I}}$ and the output current is $I_{\mathrm{DC} / \mathrm{DC}}$. The wind turbine, a 3-phase transformer, a 3-phase bridge rectifier, and a DC/DC converter are all assumed as a whole system. All of the calculations are based on the values of $V_{\mathrm{DC} / \mathrm{DC}_{I}}$ and $I_{\mathrm{DC} / \mathrm{DC}_{\mathrm{O}}}$. Since the chopper output voltages are kept constant at $48 \mathrm{~V} \mathrm{DC}$, the main variable at the output terminals of the choppers or at common DC bus is the current at the output terminals of the choppers. The output current of the chopper used to control the voltage of WES is the variable that reflects the changes on WES power. Therefore the active power generated by the WES is obtained from

$$
P_{\mathrm{DC} / \mathrm{DC}}=48 \mathrm{~V} \times I_{\mathrm{DC} / \mathrm{DC}_{\mathrm{O}}},
$$

where $48 \mathrm{~V}$ is the chopper output voltage.

All of the MPPT calculations are based on the values of $V_{\mathrm{DC} / \mathrm{DC}}$ and $I_{\mathrm{DC} / \mathrm{DC}_{O}}$. As the wind speed changes, produced power values change. Therefore, current and voltage values that belong to system have changed too. These changes are followed with the chopper and its values $V_{\mathrm{DC} / \mathrm{DC}_{I}}$ and $I_{\mathrm{DC} / \mathrm{DC}}$. By following these two values the peak power value of the system's present speed value has been determined in this way. Those loading experiments were made for all wind speed values first, and then power for each speed was determined and transferred to the controller by blurring them. Controller uses abovementioned experience and control the system properly. It is a kind of expert system behavior.

The online data collected and transferred to computer is used to determine the amount of load power demand that supplied from the PV/wind sources. In the meantime the data representing the WES quantities are used by FDM to determine the maximum power generated by the WES for the instant the measurements made. The maximum power values of both WES and PV panels are used in power management part of the study. As seen in Figure 11, the crisp current and voltage values are converted to fuzzy values. Triangle type membership functions are used to represent 7 fuzzy subsets. In the system the current values and voltage values are varying from $3,5 \mathrm{~A}$ to $23,5 \mathrm{~A}$ (from $I_{1}$ to $I_{6}$ ) and from $27 \mathrm{~V}$ to $55 \mathrm{~V}$ (from $V_{1}$ to $V_{6}$ ), respectively. The lower limit of the voltage corresponds to the lower limit of the wind speed. Below the lower limit of the voltage the required energy conversion is not satisfied. Therefore the voltages below $27 \mathrm{~V}$ 


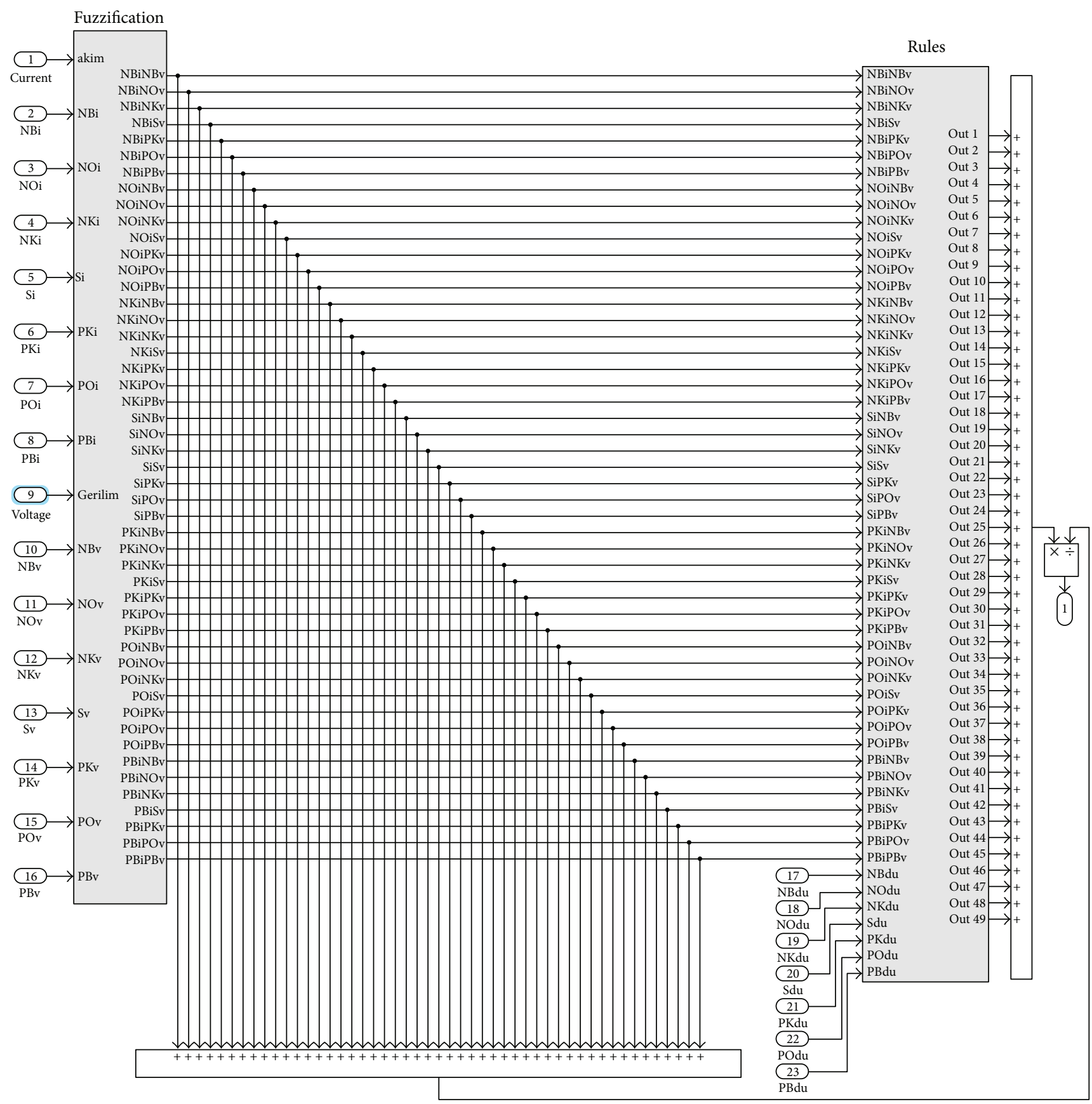

FIgUre 10: Fuzzy logic unit.

are treated as zero. The output of the FDM is the output power space (from $W_{1}$ to $W_{6}$ ) that calculates the maximum power value provided by the WES. The power generated by the WES varies as a function of the wind speed. Therefore the maximum power was obtained from the WES changes depending on the wind speed levels and must be determined for different speed levels as the wind speed changes. Therefore the maximum power surface of the WES is portioned into seven fuzzy subsurfaces as shown in Figure 12 [24].

Experimental test system is seen in Figures 13 and 14.
In WES, MPTT is implemented as software. There is not any electronic intervention to the generator. In addition to this, there is not any added hardware. For this reason, it is different from other MPTT systems.

\section{Test and Results}

In Figure 15, the system consisting of WES and PV solar panels and without energy management software can be seen. 


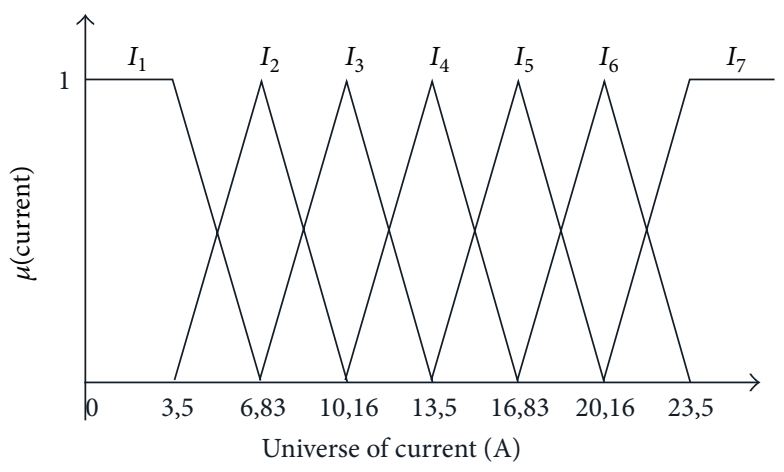

(a) Fuzzy subsets of current

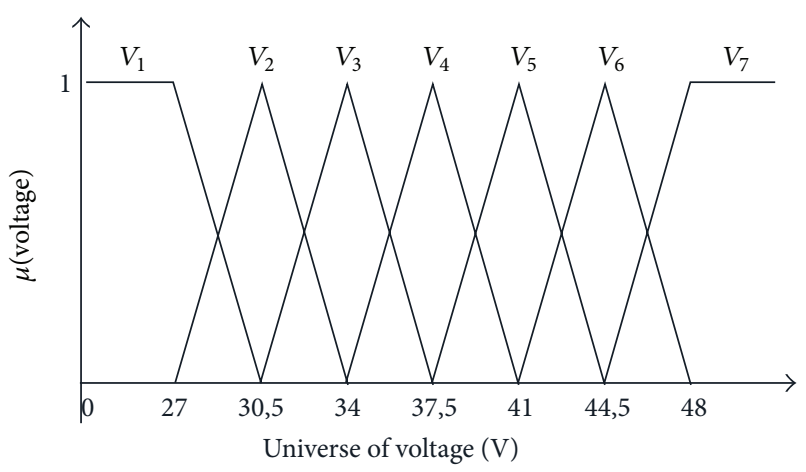

(b) Fuzzy subsets of voltages

FIGURE 11: FLR inputs.

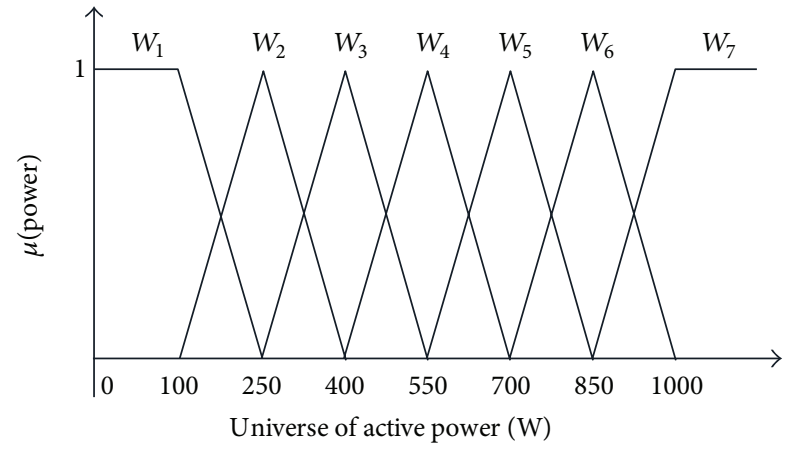

Figure 12: Fuzzy subset of power output spaces.

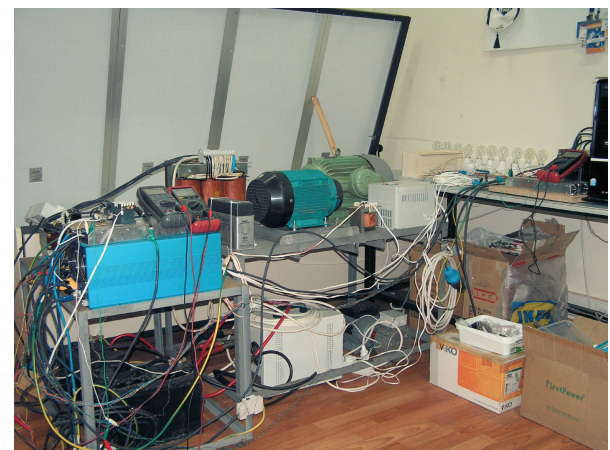

FIGURE 13: Appearance of experimental system on one side.

The system fully operates in free mode. There is neither supervision nor a control mechanism.

As the first operating case, the system is analyzed when both wind and PV solar panels are on without applying any power management. For this case, chopper input voltage, $V_{R}$, in WES, chopper output current, $I_{R}$, PV solar panel voltage, $V_{G}$, to the chopper input, chopper output current, $I_{G}$, load voltage, $V_{Y}$, and load current, $I_{Y}$, can be seen in Figures 16-18.

It can be seen that when a load power of $800 \mathrm{~W}$ is on, WES and PV system together cannot feed the loads from $40 \mathrm{~s}$ to $70 \mathrm{~s}$ and from $86 \mathrm{~s}$ to $89 \mathrm{~s}$, since they could not operate properly. Besides, the load voltage decreases

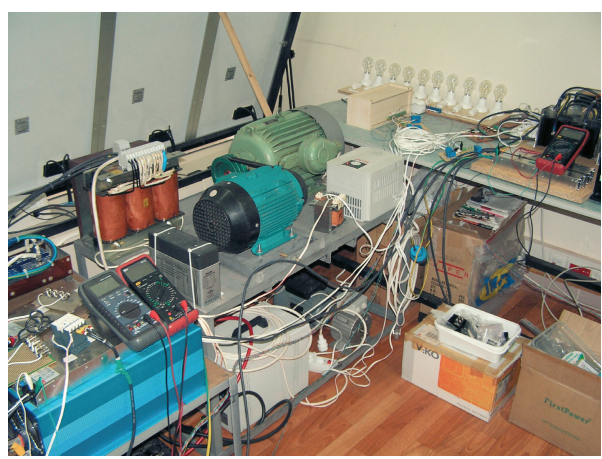

FIGURE 14: Appearance of experimental system from above.

down to 0 sometimes instead of remaining at the required value of $220 \mathrm{~V}$. Although there is enough power generated in the system, power discontinuities occur. Actually the power generated PV solar panels can be used to eliminate the power discontinuities due to changes in wind speed by applying proper power management algorithms. In this case, a decision making system is needed to control the system and make decisions in order to avoid lack of power discontinuity on loads.

The proposed power management algorithm is realized in MATLAB/Simulink environment using dynamic operational blocks library as shown in Figure 19.

The Simulink diagram in Figure 18 consists of the following subsystems:

$R I_{-}$ok: wind system current,

$R \_V \_$ok: wind system voltage,

$R \_$_ok: wind system power,

$G_{-} V_{-}$ok: PV system voltage,

G_I_ok: PV system current,

$Y \_P \_$ok: loads power,

$P$ wind_Max: calculated maximum wind power,

Grid_Switch: grid system switch (on/off),

PV_Switch: PV system switch (on/off). 


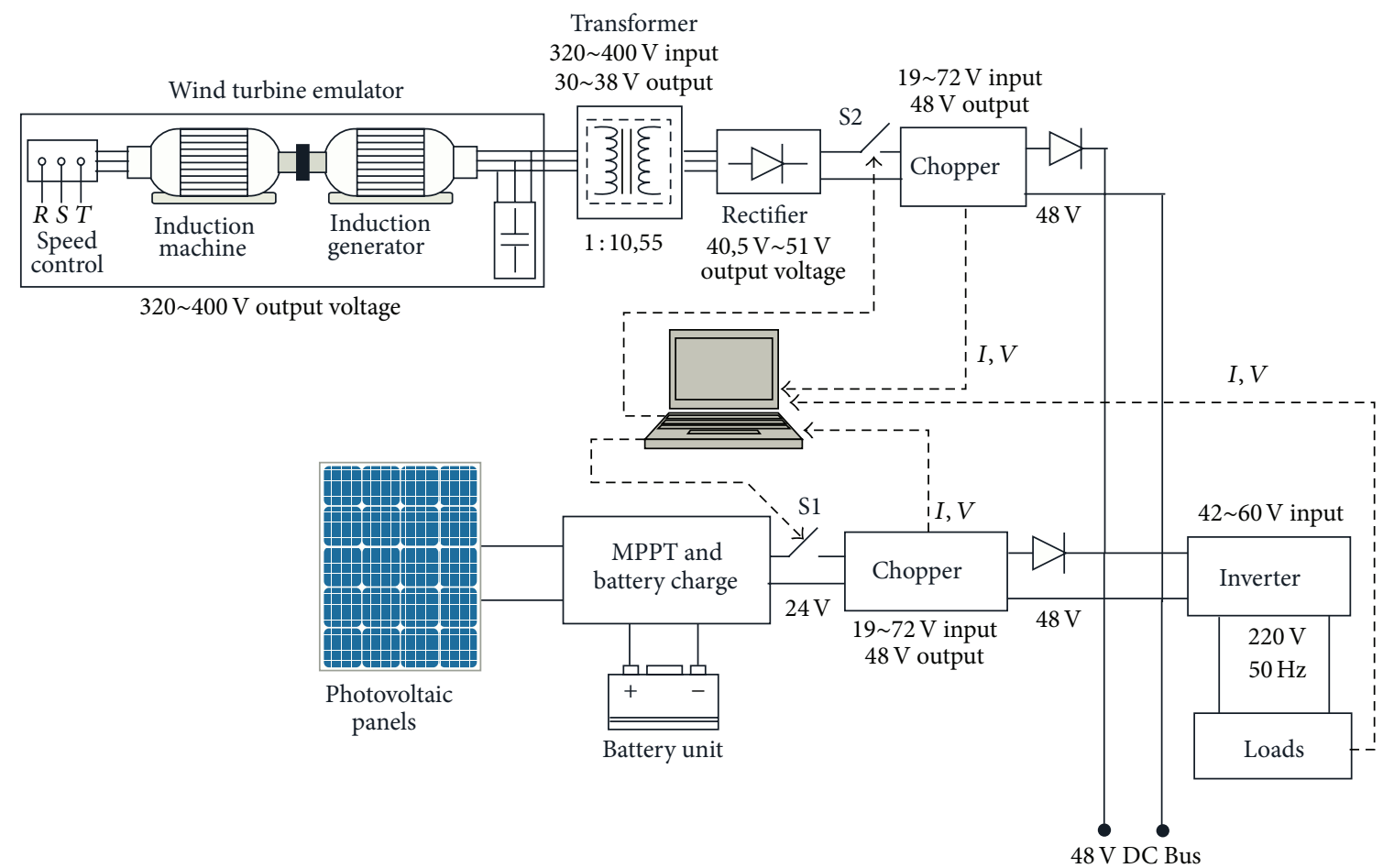

FIGURE 15: Uncontrolled wind-solar energy generation system.
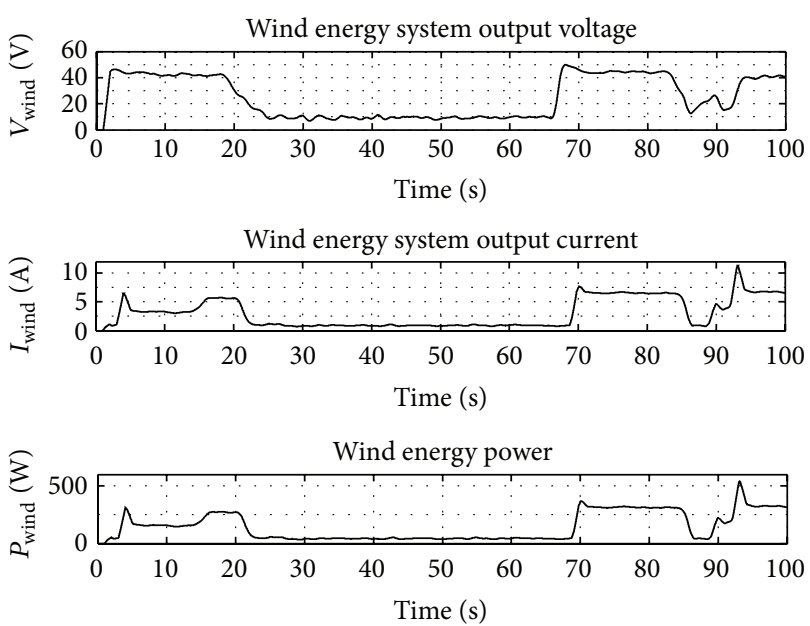

FIGURE 16: Voltage, current, and power variations of WES for case 1.

Figure 20 shows current, voltage, and power changes of WES for operating case 2 in which, the load power is changed arbitrarily in different time periods resulting in changes in the quantities of WES. It can be observed that WES is always active, yet, because of wind speed and powers extracted, the power amount transferred to the system changes.

Current, voltage, and power changes for PV system during case 2 can be seen in Figure 21. PV power is supplied to the load between the durations $t=20-75 \mathrm{~s}$ and $t=88-100 \mathrm{~s}$.
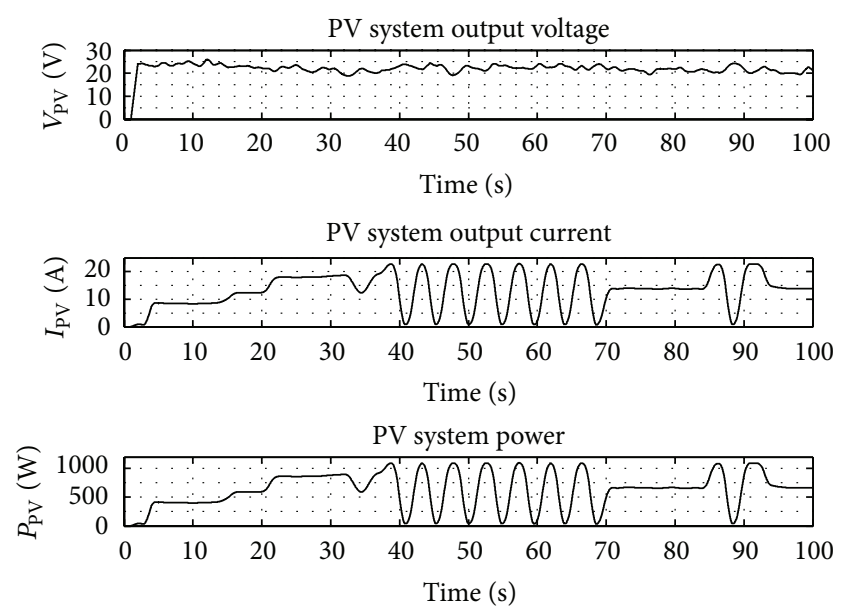

FIGURE 17: Voltage, current, and power change of PV solar panels for case 1 .

The changes of current, voltage, and power from the utility grid are given in Figure 22. The grid transfers energy to the loads during the time interval of $t=45-68 \mathrm{~s}$.

Current, voltage and power changes on the load terminals can be seen in Figure 23. The load amount changes constantly. There is a power consumption varying between $0 \mathrm{~W}$ and $900 \mathrm{~W} .100 \mathrm{~W}$ lamps are used as load. Voltage on the load is $220 \mathrm{~V}$. Varying amounts of current are taken from the energy generation system according to the load condition. 

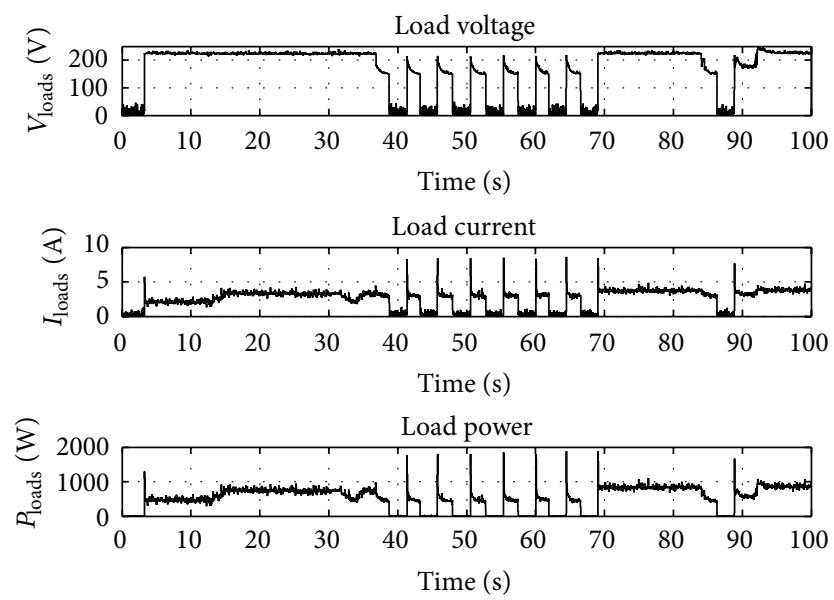

FIGURE 18: Voltage, current, and power change of loads for case 1.

In Figure 24, variation of the power generated by WES is given. A fuzzy logic reasoning (FLR) algorithm is employed to manage this power.

In Figures 25 and 26, it can be observed that PV and grid system operates and switch on and off. During the time interval of $t=41-68 \mathrm{~s}$ the PV system is on while during the time interval of $t=45-58 \mathrm{~s}$ the utility grid system feeds the loads. Both systems operate for short time periods from time to time depending upon the sudden changes.

In Figure 27, we can see the details of voltage change on the loads. Wave shape is very close to sine. Distortions are observed since data is generally taken from voltage detector.

Between Figures 28 and 37, an asynchronous motor is added to lamps which are used as load and the system is restarted and then the results are drawn. Thus, by adding resistive load and also inductive load to the system, the behavior of the system under different load conditions is examined in detail.

The current, voltage, and power value changes from WES can be seen in Figure 28. The magnitude of the generated voltage is very low in time interval from $50 \mathrm{~s}$ to $70 \mathrm{~s}$ due to high reduction in wind speed.

Time variations of voltage, current, and power of PV system are given in Figure 29. PV solar panels operate especially in period from $45 \mathrm{~s}$ to $70 \mathrm{~s}$. PV solar panels are active during this period because WES is not sufficient enough to generate the required load power.

Figure 30 shows the variations of voltage, current, and power of the utility grid. During the period from $45 \mathrm{~s}$ to $75 \mathrm{~s}$ the utility grid supplies power to the loads since both wind and PV systems are off or they do not generate required power due to low speed and/or low sunlight.

Current, voltage, and power changes on the load can be seen in Figure 31. Asynchronous motor load is always kept operating. During the time interval of $t=3-18 \mathrm{~s}$, $200 \mathrm{~W}$ lamps are added to the system as loads in addition to the asynchronous motor. Later, in period $t=27-85 \mathrm{~s}$, the lamps are turned off leaving only the asynchronous motors as the load. Meanwhile, wind speed is changed constantly.
Load voltage is kept at $220 \mathrm{~V}$, while the load current varies according to load condition.

The maximum power drawn from the WES is given in Figure 32. The generated power by WES is high around 900$950 \mathrm{~W}$ when the wind speed is high and it is low around $200 \mathrm{~W}$ when the wind speed is lower during the period from $50 \mathrm{~s}$ to $70 \mathrm{~s}$.

The on and off switching instances of PV solar panels and utility grid system are shown Figures 33 and 34, respectively. In period of $t=40-70 \mathrm{~s}, \mathrm{PV}$ panels are on and, in period of $t=43-70 \mathrm{~s}$, the grid system is on. They are turned on in order to support WES so that the loads will not be lacking of energy in that time period.

Wave shape details of voltage on the load are given in Figure 35. Although elements like asynchronous motor lead to harmonics, a very clear sine wave with a little amount of distortion is obtained.

The variations of power from wind, $\mathrm{PV}$, and load busses are given in Figure 36 for case 1 where there is neither control nor power management algorithm. Since there is no power management, the load tries to get the power from PV and backup system, which are not sufficient enough to feed the load. Therefore load does not get the required power to operate.

Variations of the power from WES, PV, and utility grid along with load power and available maximum value of the wind power are shown in Figure 37. Proposed power management algorithm (PMA) has been applied for this case. Therefore there is no problem on supplied load power. As load or environmental conditions change, the load power is supplied from the sources in the order of priority use as wind, $\mathrm{PV}$, and utility grid. If the power from the wind is sufficient for the load, the generated PV power is stored in backup batteries. If the wind power is not sufficient, then PV power is connected to complete the required power. If both wind and $\mathrm{PV}$ do not generate the required load power, then the utility grid is connected.

\section{Conclusions}

An intelligent energy management system (IEMS) for maintaining the energy sustainability in renewable energy systems is presented in this study. A renewable energy system consisting of wind and PV panels is established and used to test the proposed IEMS. Since the wind and PV sources are not reliable in terms of sustainability and power quality, a management system is required for sustainability on the load side. The proposed PMA is used to collect power from renewable sources and utility grid at a common DC bus and feed the loads preventing any power discontinuity. By employing PMA, a base power is always supplied to DC bus to be used by the loads that are operating permanently. Besides, PMA handles the effects of the changes in wind speed, solar irradiation, and amount of the load by operating wind, PV, and utility grid accordingly using intelligent decision making abilities. The proposed intelligent PMA is also used to determine and track the generated and available maximum wind power from WES so that the efficiency of 


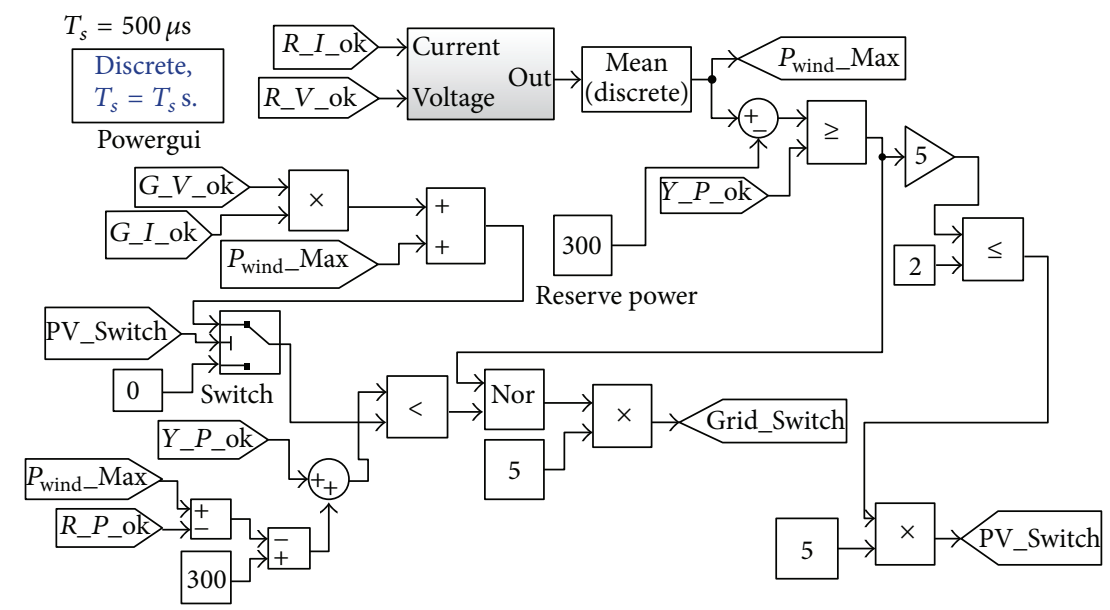

FIGURE 19: Simulink model of the proposed power management system.
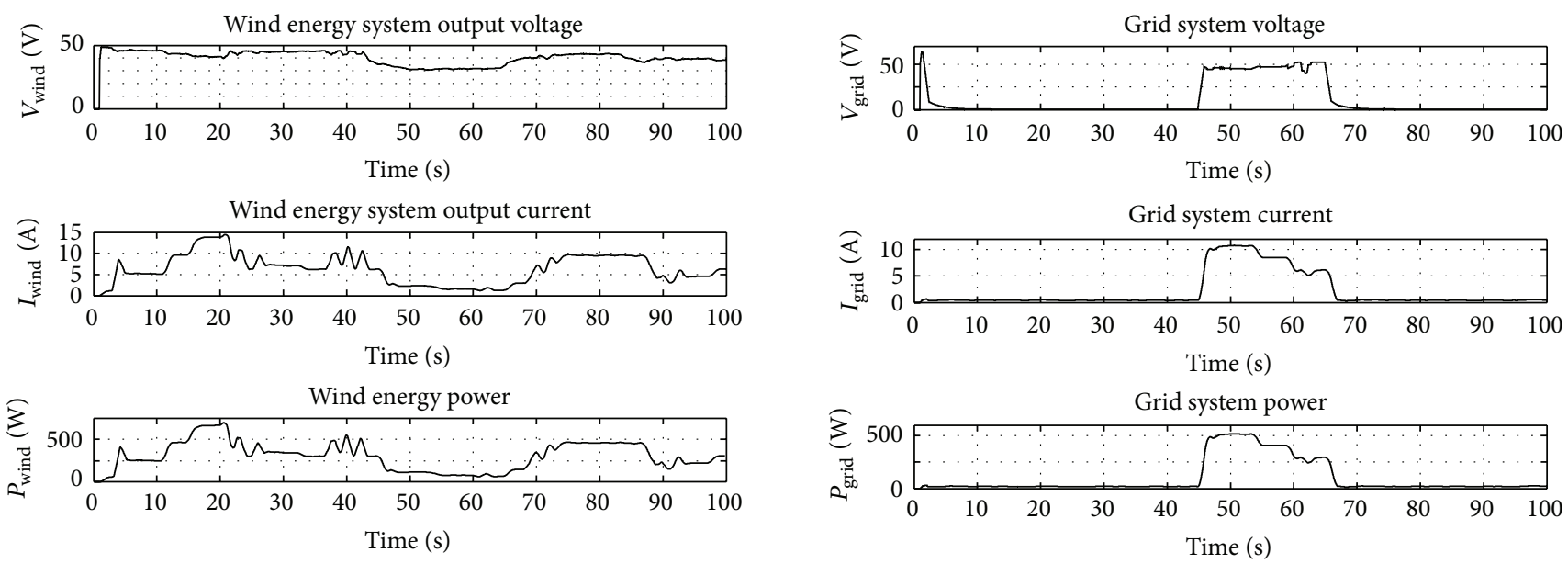

FIGURE 20: Current, voltage, and power change in WES for case 2.

FIGURE 22: Variations of current, voltage, and power from the utility grid in case 2 .
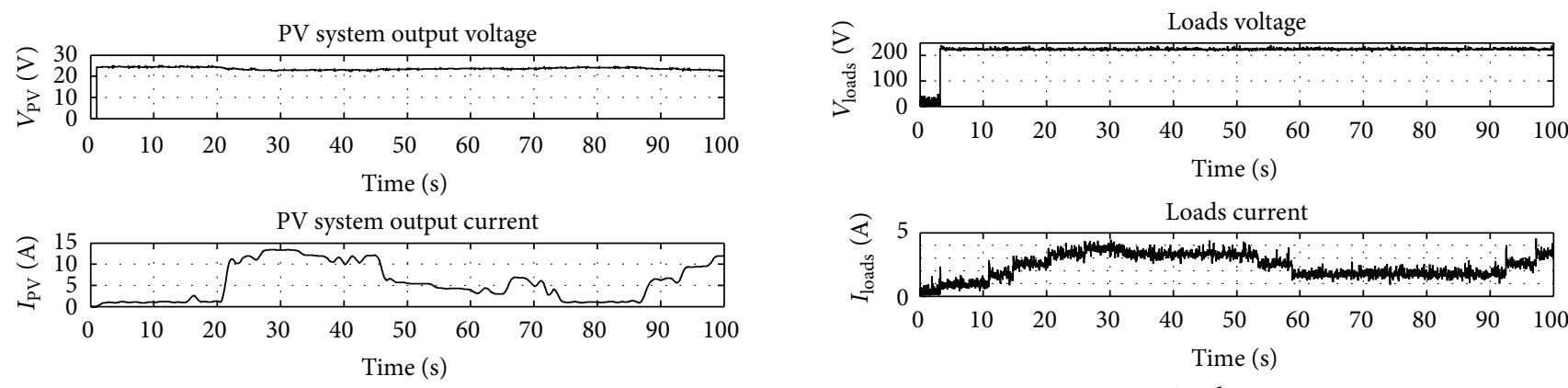

PV system power

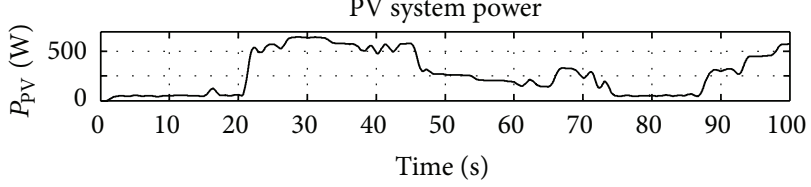

FIGURE 21: Current, voltage, and power change of PV system in case 2.

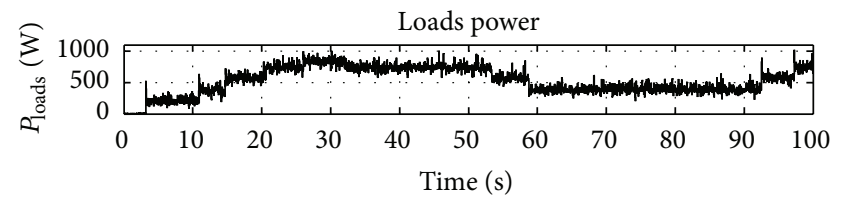

FIGURE 23: Current, voltage, and power change on the load in case 2 . 


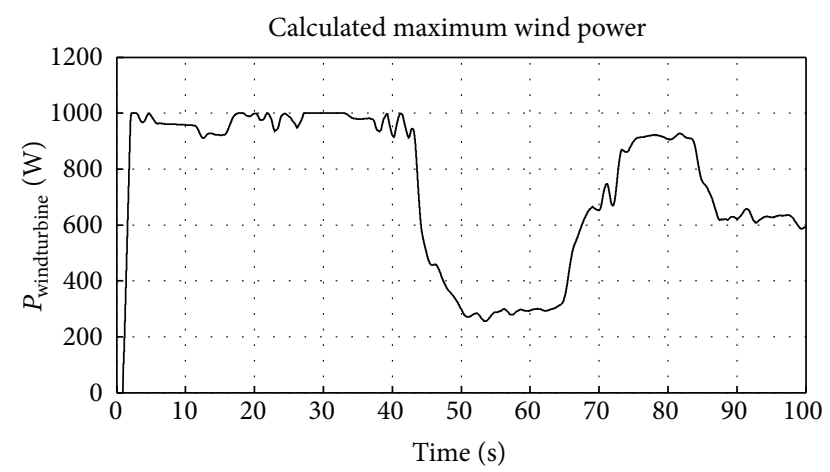

FIGURe 24: Peak power changes obtained from WES using FLR algorithm.

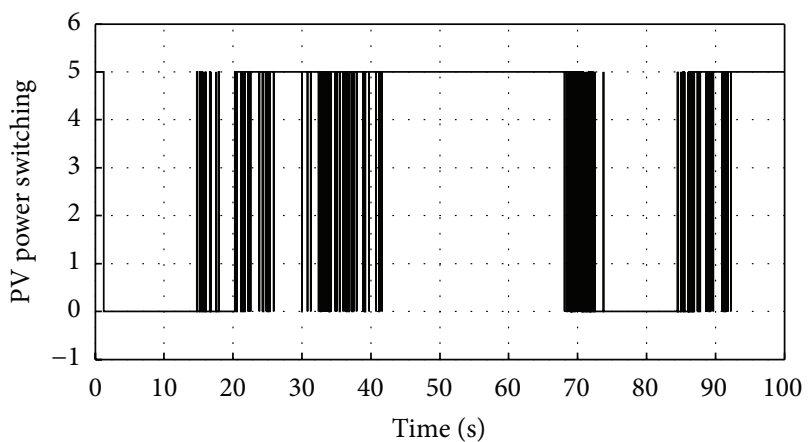

FIGURE 25: Switching instants of PV system when wind energy is not sufficient.

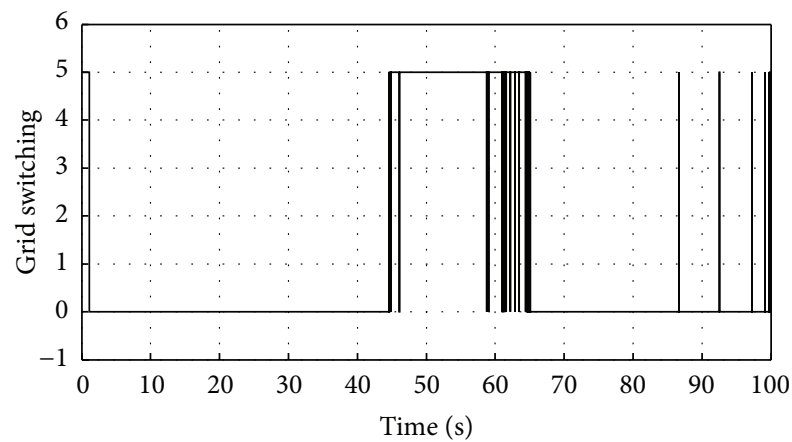

FIGURE 26: Switching instants of utility grid when wind and solar energy are not sufficient.

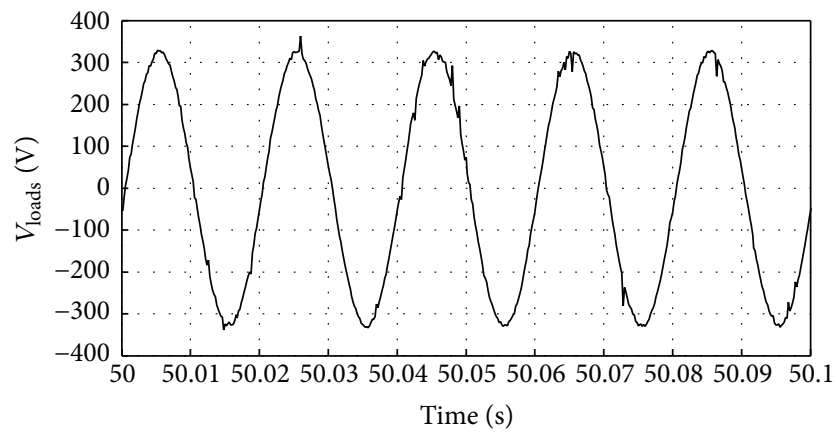

FIGURE 27: Wave shape of the voltage on loads.
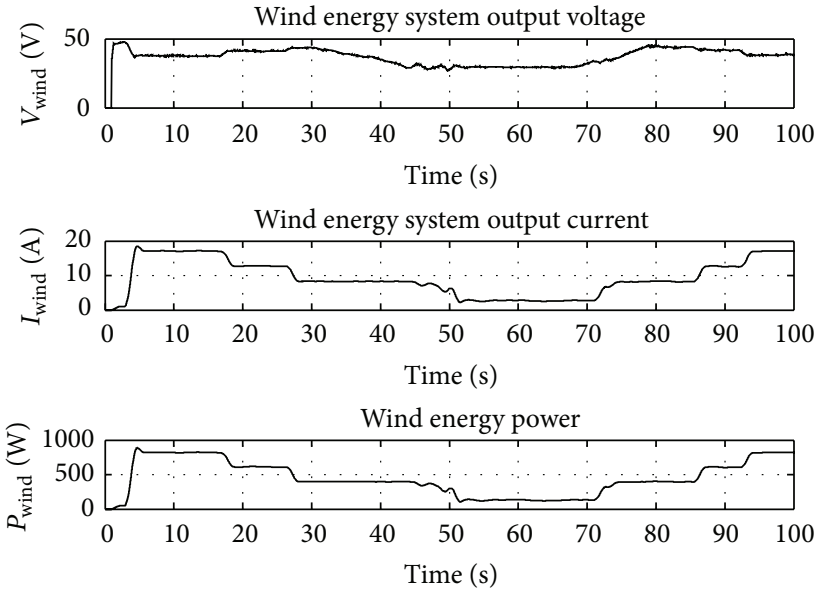

FIGURE 28: Current, voltage, and power changes of wind energy system.
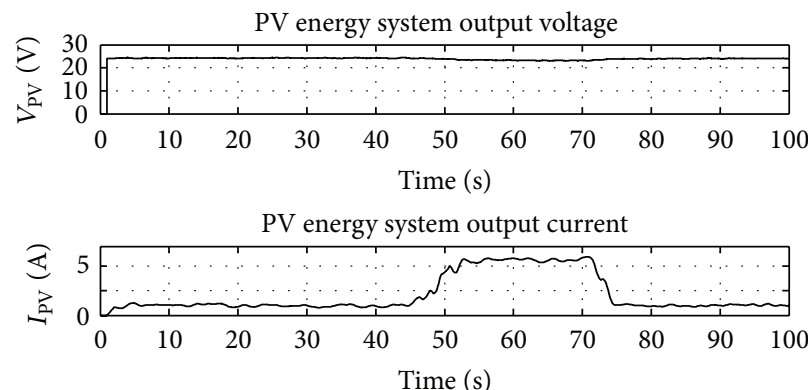

Time (s)

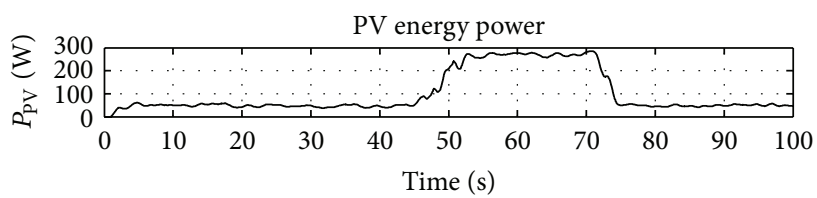

FIGURE 29: Current, voltage, and power change of PV energy system.
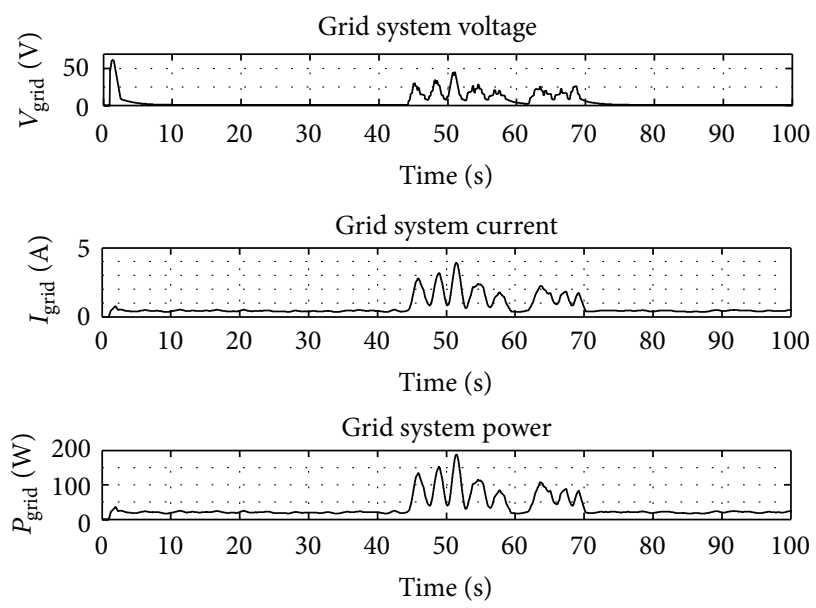

Figure 30: Current, voltage, and power change of grid system. 

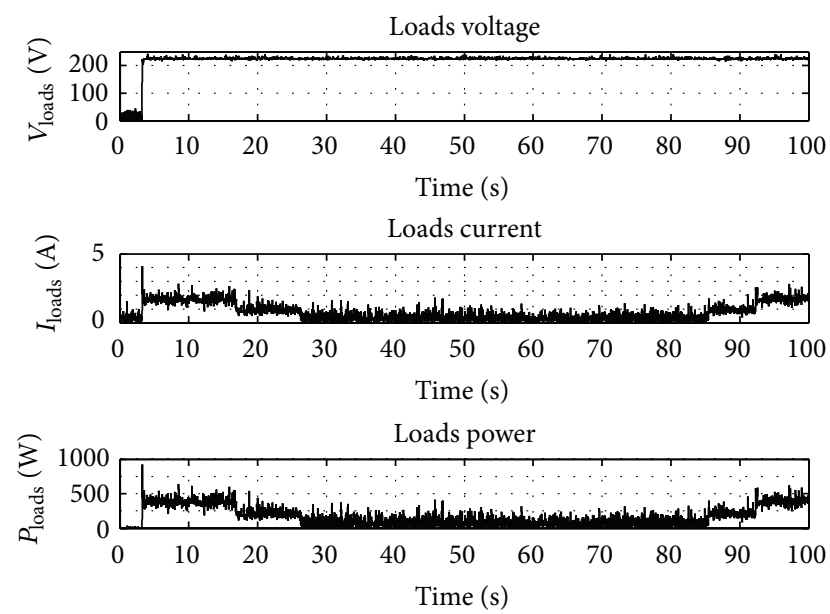

Figure 31: Current, voltage, and power change on the loads.

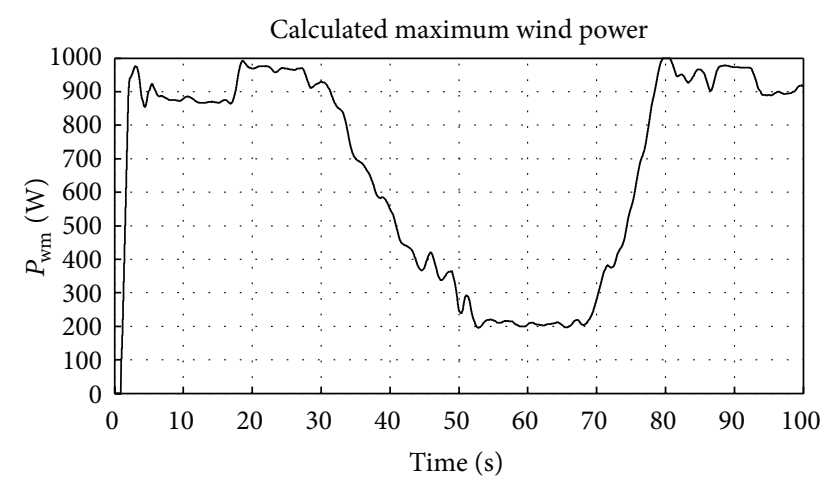

FIGURE 32: The maximum power change tracking of the WES by FLR.

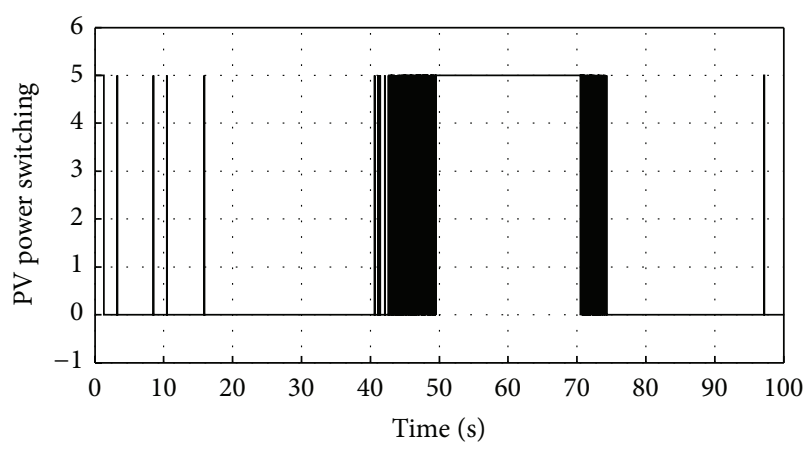

FIGURE 33: On and off switching pulses of PV panels.

the installed units is increased. Using the generated and required power information from the wind/PV and load sides, the fuzzy reasoning based PMA generates the required operating sequences to manage the overall system power with the minimum requirement from the utility. The IPMS is also designed to operate the renewable energy systems

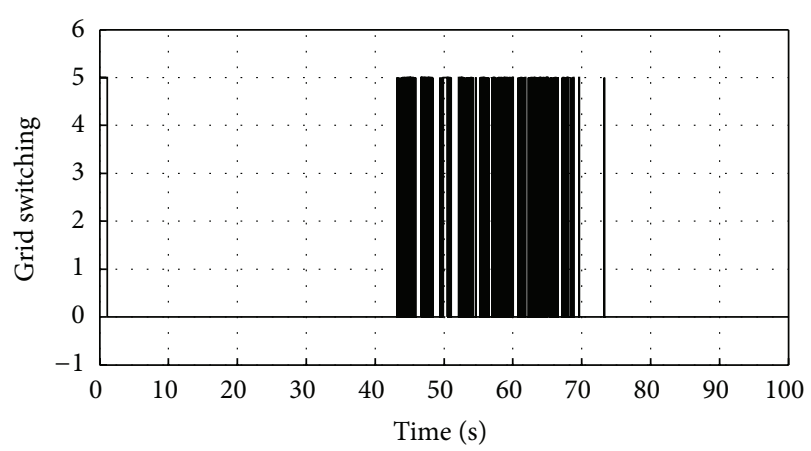

FIGURE 34: On and off switching pulses of utility grid.

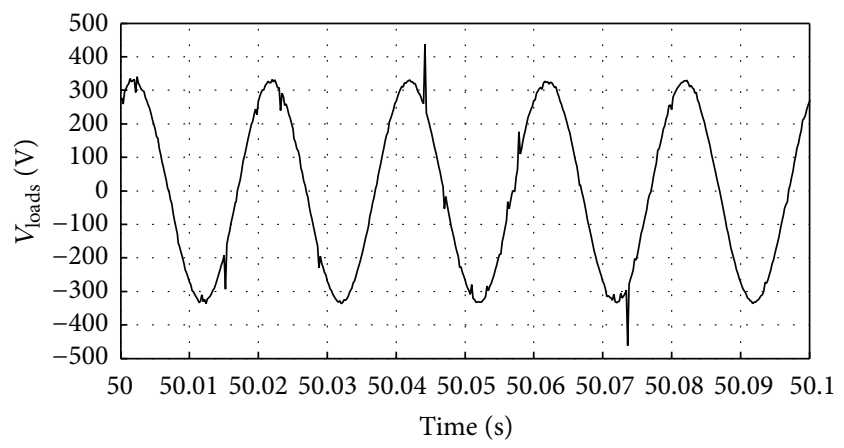

FIGURE 35: Voltage wave shape on the load.
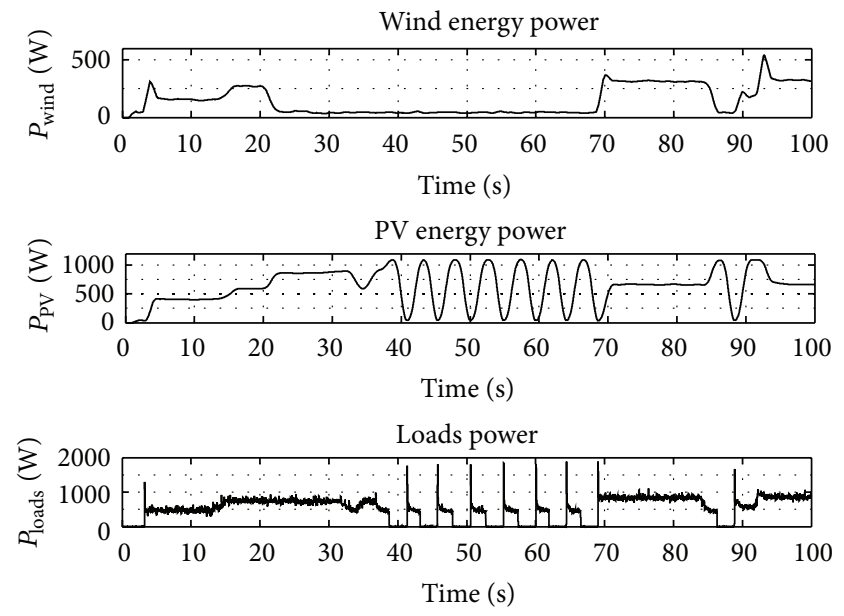

FIGURE 36: Power changes in the system without power management.

as a part of power utility. Therefore the IEMS can also be considered as a smart grid operator in the proposed RES application. Proposed IPMS can be extended to be used in distributed power systems for providing decisions on power management during critical peak power instances and fast power demand changes. 

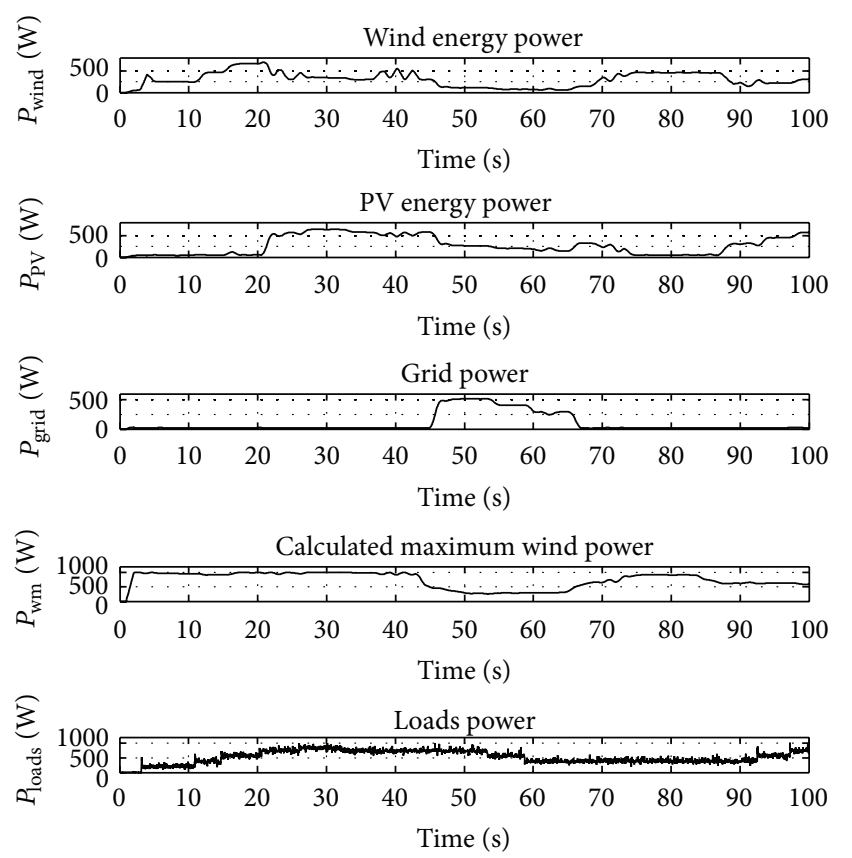

FIGURE 37: Power changes under only resistive loads condition in developed power management program in solar-wind-grid system.

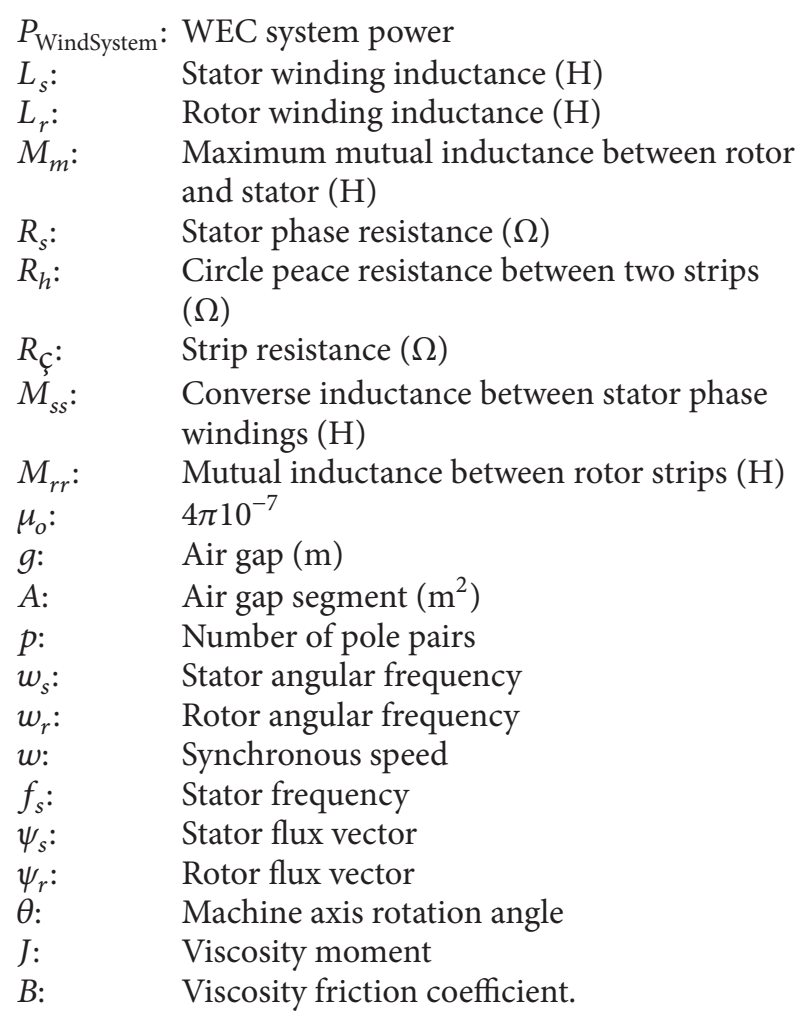

Nomenclature

IEMS: Intelligent energy management system

PMS: Power management system

PMA: Power management algorithm

RES: Renewable energy systems

PV: $\quad$ Photovoltaic

PVES: Photovoltaic energy system

MPPT: Maximum power point tracking

WES: Wind energy system

DC: Direct current

AC: Alternative current

FLR: Fuzzy logic reasoning

FDM: Fuzzy decision maker.

\section{Conflict of Interests}

The authors declare that there is no conflict of interests regarding the publication of this paper.

\section{Acknowledgment}

This study was supported by Karadeniz Technical University Scientific Research Projects Unit, Project no. 2008.112.004.2.

\section{References}

[1] P. Denholm, R. Margolis, T. Mai et al., "Bright future: solar power as a major contributor to the U.S. grid," IEEE Power and Energy Magazine, vol. 11, no. 2, pp. 22-32, 2013.

[2] J. Von Appen, M. Braun, T. Stetz, K. Diwold, and D. Geibel, "Time in the sun: the challenge of high PV penetration in the 
German electric grid," IEEE Power and Energy Magazine, vol. 11, no. 2, pp. 55-64, 2013.

[3] K. Ogimoto, I. Kaizuka, Y. Ueda, and T. Oozeki, "A good fit: Japan's solar power program and prospects for the new power system," IEEE Power and Energy Magazine, vol. 11, no. 2, pp. 6574, 2013.

[4] V. Quasching, Understanding Renewable Energy Systems, Earthscan, London, UK, 2005.

[5] T. Ackermann, Wind Power in Power Systems, John Wiley \& Sons, Chichester, UK, 2005.

[6] I. Akova, Yenilenebilir Enerji Kaynakları, Nobel Yayin Dagitim, Ankara, Turkey, 2008.

[7] C. Kocatepe, M. Uzunoğlu, R. Yumurtac1, A. Karakaş, and O. Arikan, Elektrik Tesislerinde Harmonikler, Birsen Yayınevi, Istanbul, Turkey, 2003.

[8] T. Esram and P. L. Chapman, "Comparison of photovoltaic array maximum power point tracking techniques," IEEE Transactions on Energy Conversion, vol. 22, no. 2, pp. 439-449, 2007.

[9] G. M. Masters, Renewable and Efficient Electric Power Systems, John Wiley \& Sons, New York, NY, USA, 2004.

[10] J. L. Bernal-Agustín, R. Dufo-López, J. A. Domínguez-Navarro, and J. M. Yusta-Loyo, "Optimal design of a PV-wind system for water pumping," in Proceedings of the International Conference on Renewable Energies and Power Quality, pp. 1-6, Santander, Spain, March 2008.

[11] Y. Thiaux, J. Seigneurbieux, B. Multon, H. B. Ahmed, and D. Miller, "Single phase AC power load profile emulator," in Proceedings of the International Conference on Renewable Energies and Power Quality, Santander, March 2008.

[12] V. Courtecuisse, J. Sprooten, B. Robyns, M. Petit, B. Francois, and J. Deuse, "A methodology to design a fuzzy logic based supervision of hybrid renewable energy systems," Mathematics and Computers in Simulation, vol. 81, no. 2, pp. 208-224, 2010.

[13] Y. Chen and J. Wu, "Agent-based energy management and control of a grid-connected wind/solar hybrid power system," in Proceedings of the 11th International Conference on Electrical Machines and Systems (ICEMS '08), pp. 2362-2365, IEEE, Wuhan, China, October 2008.

[14] D. Das, R. Esmaili, L. Xu, and D. Nichols, "An optimal design of a grid connected hybrid wind/photovoltaic/fuel cell system for distributed energy production," in Proceedings of the 31st Annual Conference of IEEE Industrial Electronics Society (IECON '05), pp. 2499-2504, November 2005.

[15] X. Zhu, D. Xu, P. Wu, G. Shen, and P. Chen, "Energy management design for a $5 \mathrm{~kW}$ fuel cell distributed power system," in Proceedings of the 23rd Annual IEEE Applied Power Electronics Conference and Exposition, pp. 291-297, Austin, Tex, USA, February 2008.

[16] K.-S. Jeong, W.-Y. Lee, and C.-S. Kim, "Energy management strategies of a fuel cell/battery hybrid system using fuzzy logics," Journal of Power Sources, vol. 145, no. 2, pp. 319-326, 2005.

[17] Z. Jiang, "Power management of hybrid photovoltaic-fuel cell power systems," in Proceedings of the IEEE Power Engineering Society General Meeting, pp. 1-6, June 2006.

[18] M. Nayeripour, M. Hoseintabar, T. Niknam, and J. Adabi, "Power management, dynamic modeling and control of wind/FC/battery-bank based hybrid power generation system for stand-alone application," European Transactions on Electrical Power, vol. 22, no. 3, pp. 271-293, 2012.

[19] S. Harrington and J. Dunlop, "Battery charge controller characteristics in photovoltaic systems," in Proceedings of the 7th
Annual Battery Conference on Applications and Advances, pp. 15-21, Pasadena, Calif, USA, January 1992.

[20] S. Eren, J. C. Y. Hui, D. To, and D. Yazdani, "A high performance wind-electric battery charging system," in Proceedings of the Canadian Conference on Electrical and Computer Engineering (CCECE '06), pp. 2275-2277, Ottawa, Canada, May 2006.

[21] D. B. Nelson, M. H. Nehrir, and C. Wang, "Unit sizing of standalone hybrid Wind/PV/fuel cell power generation systems," in Proceedings of the 2005 IEEE Power Engineering Society General Meeting, pp. 2116-2122, San Francisco, Calif, USA, June 2005.

[22] R. Contino, F. Iannone, S. Leva, and D. Zaninelli, "Hybrid photovoltaic-fuel cell system controller sizing and dynamic performance evaluation," in Proceedings of the IEEE Power Engineering Society General Meeting, pp. 1-6, Montreal, Canada, October 2006.

[23] Q. Mei, W.-Y. Wu, and Z.-L. Xu, "A multi-directional power converter for a hybrid renewable energy distributed generation system with battery storage," in Proceedings of the CES/IEEE 5th International Power Electronics and Motion Control Conference (IPEMC 2006), pp. 1932-1936, Shanghai, China, August 2006.

[24] I. H. Altas and O. O. Mengi, "A fuzzy logic controller for a hybrid PV/FC green power system," International Journal of ReasoningBased Intelligent Systems, vol. 2, no. 3, pp. 176-183, 2010.

[25] D. Petkovića, S. Shamshirbandb, N. B. Anuar et al., "An appraisal of wind speed distribution prediction by soft computing methodologies: a comparative study," Energy Conversion and Management, vol. 84, pp. 133-139, 2014.

[26] O. O. Mengi and I. H. Altas, "A fuzzy decision making energy management system for a PV/Wind renewable energy system," in Proceedings of the International Symposium on Innovations in Intelligent Systems and Applications (INISTA '11), pp. 436-440, IEEE, Istanbul, Turky, June 2011.

[27] I. Munteanu, A. I. Bratcu, and E. Ceangǎ, "Wind turbulence used as searching signal for MPPT in variable-speed wind energy conversion systems," Renewable Energy, vol. 34, no. 1, pp. 322-327, 2009.

[28] V. Galdi, A. Piccolo, and P. Siano, "Exploiting maximum energy from variable speed wind power generation systems by using an adaptive Takagi-Sugeno-Kang fuzzy model," Energy Conversion and Management, vol. 50, no. 2, pp. 413-421, 2009.

[29] T. Senjyu, Y. Ochi, Y. Kikunaga et al., "Sensor-less maximum power point tracking control for wind generation system with squirrel cage induction generator," Renewable Energy, vol. 34, no. 4, pp. 994-999, 2009.

[30] M. Arifujjaman, M. T. Iqbal, and J. E. Quaicoe, "Maximum power extraction from a small wind turbine emulator using a DC-DC converter controlled by a microcontroller," in Proceedings of the 4th International Conference on Electrical and Computer Engineering (ICECE '06), pp. 213-216, Dhaka, Bangladesh, December 2006.

[31] V. Calderaro, V. Galdi, A. Piccolo, and P. Siano, "A fuzzy controller for maximum energy extraction from variable speed wind power generation systems," Electric Power Systems Research, vol. 78, no. 6, pp. 1109-1118, 2008.

[32] V. Agarwal, R. K. Aggarwal, P. Patidar, and C. Patki, "A novel scheme for rapid tracking of maximum power point in wind energy generation systems," IEEE Transactions on Energy Conversion, vol. 25, no. 1, pp. 228-236, 2010.

[33] V. Agarwal, R. K. Aggarwal, P. Patidar, and C. Patki, "A novel scheme for rapid tracking of maximum power point in wind energy generation systems," IEEE Transactions on Energy Conversion, vol. 25, no. 1, pp. 228-236, 2010. 
[34] M. K. Sarığlu, M. Gökaşan, and S. Boğosyan, Asenkron Makinalar ve Kontrolü, Birsen Yayınevi, Istanbul, Turkey, 2003.

[35] O. O. Mengi, Yenilenebilir Enerji Sistemlerinde Süreklilik için Akıllı Bir Enerji Yönetim Sistemi [Ph.D. thesis], Karadeniz Technical University, Trabzon, Turkey, 2011. 

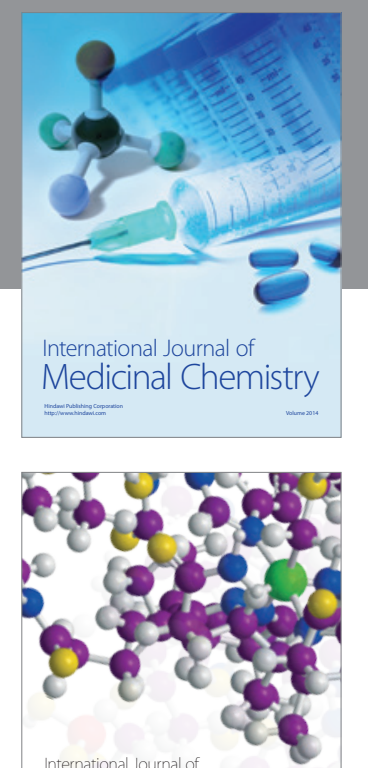

\section{Carbohydrate} Chemistry

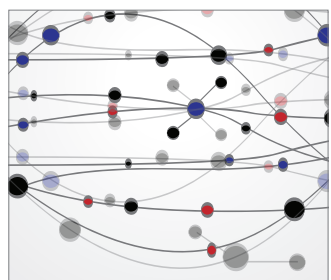

The Scientific World Journal
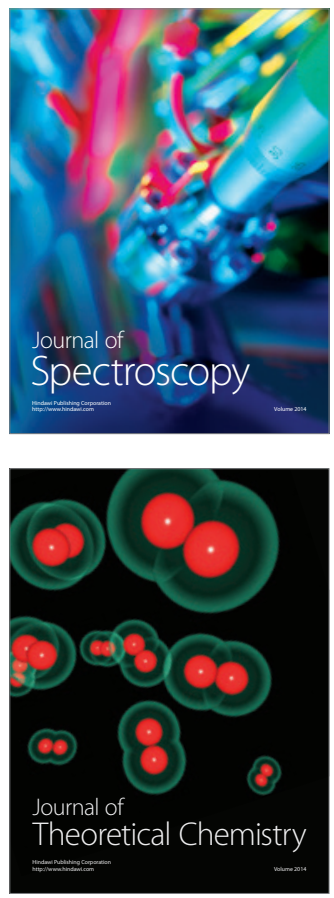
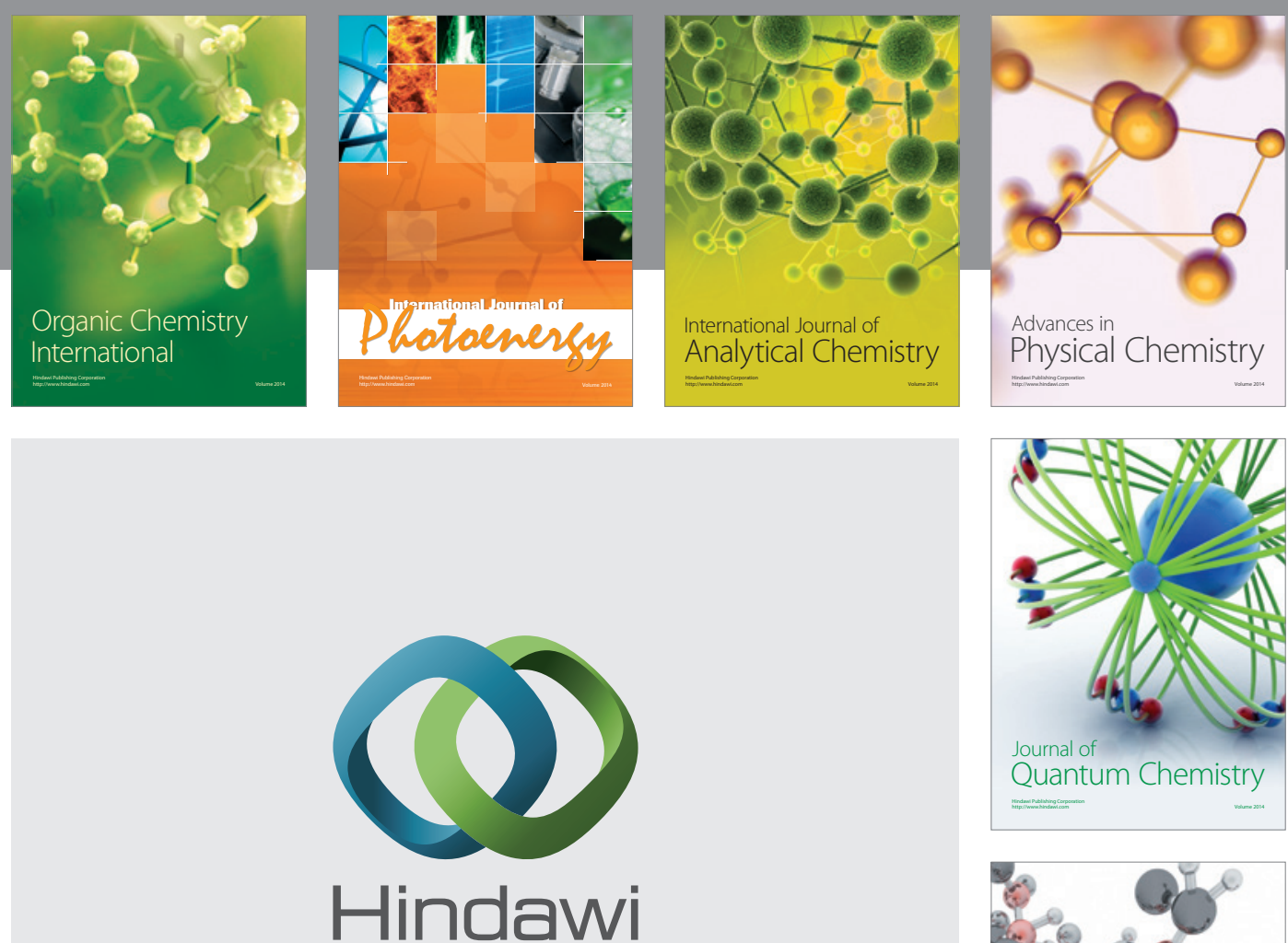

Submit your manuscripts at

http://www.hindawi.com

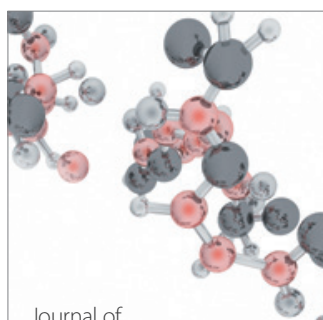

Analytical Methods

in Chemistry

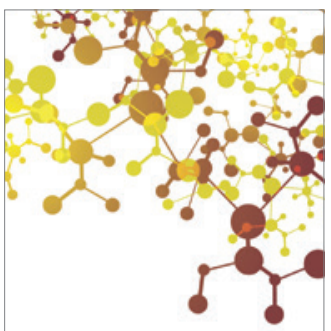

Journal of

Applied Chemistry

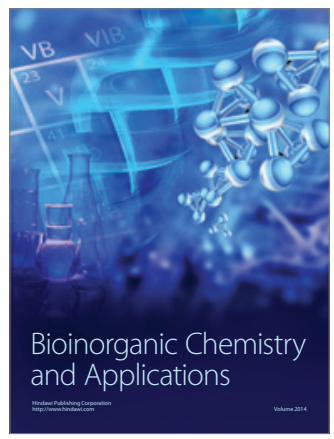

Inorganic Chemistry
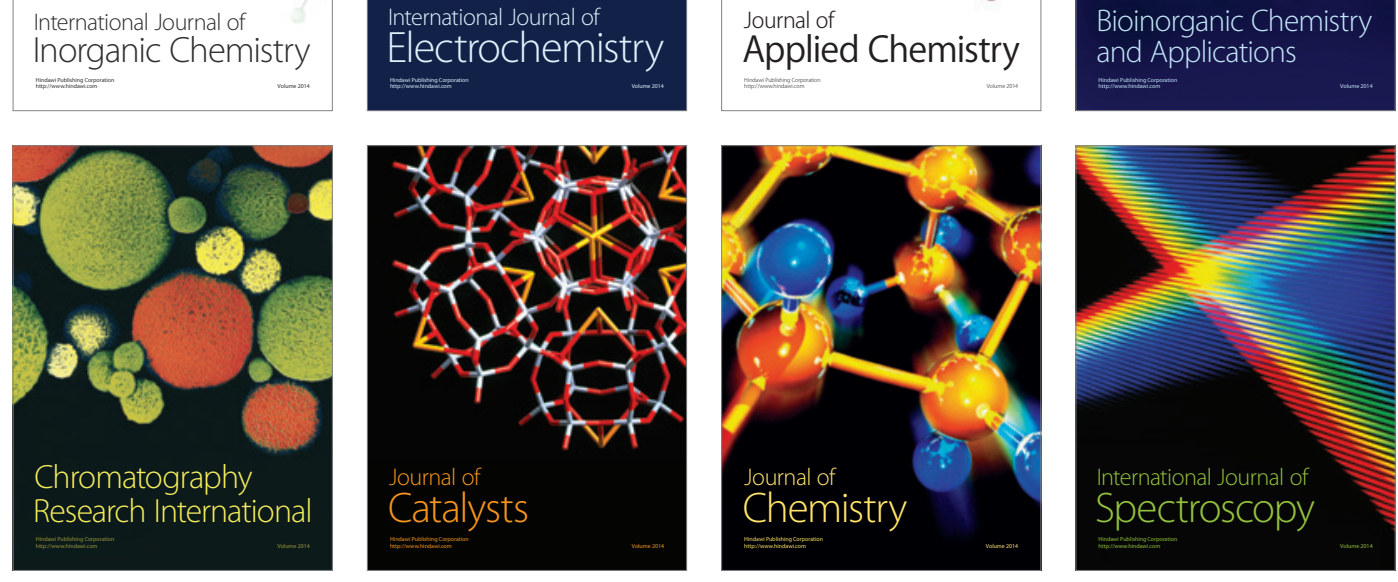